09,04

\title{
Спектральные и структурные характеристики вольфраматов $\left(\mathrm{Lu}_{1-x} \mathrm{Eu}_{x}\right)_{2}\left(\mathrm{WO}_{4}\right)_{3}$
}

\author{
() С.З. Шмурак, В.В. Кедров, А.П. Киселев, Т.Н. Фурсова, И.И. Зверькова, С.С. Хасанов \\ Институт физики твердого тела РАН, \\ Черноголовка, Россия \\ E-mail: shmurak@issp.ac.ru
}

Поступила в Редакцию 17 июня 2019 г.

В окончательной редакции 17 июня 2019 г.

Принята к публикации 17 июня 2019 г.

\begin{abstract}
Проведены исследования структуры, спектров люминесценции и ИК-спектров поглощения твердых растворов $\left(\mathrm{Lu}_{1-x} \mathrm{Eu}_{x}\right)_{2}\left(\mathrm{WO}_{4}\right)_{3}$ в широком диапазоне концентраций европия $(0 \leq x \leq 1)$. С ростом концентрации европия происходит последовательная смена двух типов кристаллических фаз. Орторомбическая фаза (пр. гр. $P b c n$ ) твердых растворов вольфраматов наблюдается при $0 \leq x<0.5$. В интервале значений $0.5 \leq x \leq 0.8$ наряду с орторомбической появляется моноклинная фаза (пр. гр. $C 2 / c$ ), а при $x>0.8$ твердый раствор имеет моноклинную структуру. Установлено соответствие между структурой и спектральными характеристиками этих соединений. Изменение структурного состояния приводит не только к изменению спектров люминесценции, но и спектров возбуждения люминесценции вольфраматов. В связи с гидрофильностью твердых растворов $\left(\mathrm{Lu}_{1-x} \mathrm{Eu}_{x}\right)_{2}\left(\mathrm{WO}_{4}\right)_{3}$ изучена изотерма адсорбции воды образцами вольфраматов и ее влияние на их спектральные и структурные характеристики. Установлено, что максимум свечения при резонансном возбуждении ионов $\mathrm{Eu}^{3+}$ наблюдается в образцах с моноклинной структурой $C 2 / c$ при $x \sim 0.9$.
\end{abstract}

Ключевые слова: люминофоры для светодиодов, вольфраматы редкоземельных элементов, рентгенофазовый анализ, ИК-спектроскопия, спектры люминесценции.

DOI: 10.21883/FTT.2019.11.48420.516

\section{1. Введение}

Возможность направленного изменения спектральных характеристик материалов крайне важна при изготовлении светодиодных источников „белого“ света (white light emitting diodes, WLED). Решение этой проблемы может быть реализовано путем изменения структурного состояния материала. Действительно, как показано в ряде работ [1-6], каждой структурной модификации различных полиморфных соединений молибдатов, боратов, содержащих оптически активные центры, соответствует строго определенный спектр люминесценции (СЛ). Например, при фотовозбуждении кальцитной модификации $\mathrm{LuBO}_{3}: \mathrm{Eu}$ наблюдается полоса с $\lambda_{\max } \sim 590 \mathrm{~nm}$ и в 3 раза менее интенсивная полоса $\sim 596 \mathrm{~nm}$, тогда как СЛ ватеритной структуры $\mathrm{LuBO}_{3}: \mathrm{Eu}$ содержит ряд линий, сгруппированных в 3 полосы примерно одинаковой интенсивности, в области длин волн $\sim 593,611$ и $628 \mathrm{~nm}$ [7-10], поэтому для кальцитной и ватеритной модификаций $\mathrm{LuBO}_{3}: \mathrm{Eu}$ характерно оранжевое и красное свечение соответственно.

В работе [11] проведены исследования структуры, спектров люминесценции и ИК-спектров поглощения твердых растворов состава $\left(\mathrm{Lu}_{1-x} \mathrm{Eu}_{x}\right)_{2}\left(\mathrm{MoO}_{4}\right)_{3}$ в широком диапазоне концентраций $\mathrm{Eu}(0 \leq x \leq 1)$. В этих соединениях также установлено соответствие между структурным состоянием и спектральными характеристиками исследованных образцов. При $x<0.2$ твердый раствор $\left(\mathrm{Lu}_{1-x} \mathrm{Eu}_{x}\right)_{2}\left(\mathrm{MoO}_{4}\right)_{3}$ имеет моноклинную структуру - пространственная группа (пр.гр.) $P 2_{1} / a$.
Соответствующий этой структуре СЛ содержит 3 полосы с $\lambda_{\max } \sim 608.3, \sim 612.4$ и $\sim 616.6 \mathrm{~nm}$. При увеличении доли европия в диапазоне $0.2<x<0.4$ происходит переход соединения $\left(\mathrm{Lu}_{1-x} \mathrm{Eu}_{x}\right)_{2}\left(\mathrm{MoO}_{4}\right)_{3}$ в орторомбическую структуру (пр.гр. Pbcn). В СЛ этого соединения наибольшую интенсивность имеют только две полосы: с $\lambda_{\max } \sim 608.3$ и $612.4 \mathrm{~nm}$. Моноклинная фаза (пр.гр. $P 21 / a$ ) представляет собой незначительно искаженную более высокосимметричную орторомбическую фазу (пр.гр. Pbcn). В обеих этих структурах оптически активный ион $\mathrm{Eu}^{3+}$ окружают 6 анионов кислорода. Вместе с тем, в моноклинной структуре для редкоземельного (RE) иона существуют 4 неэквивалентные позиции [12], тогда как в орторомбической фазе (пр.гр. Pbcn) для редкоземельного иона имеется только одна позиция [13]. Эти различия, согласно [11], являются причиной уширения спектральных линий в моноклинной структуре и появления новой широкой полосы $\lambda_{\max } \sim 616.6 \mathrm{~nm}$.

Значительные изменения СЛ $\left(\mathrm{Lu}_{1-x} \mathrm{Eu}_{x}\right)_{2}\left(\mathrm{MoO}_{4}\right)_{3}$ происходят при $x>0.5$. Это соединение имеет также орторомбическую структуру (пр.гр. Рba2), однако ее плотность на $12 \%$ больше плотности орторомбической фазы с пр.гр. Pbcn. Наиболее существенным отличием этих структур, определяющим свойства материала, является различное число атомов кислорода, окружающих редкоземельные ионы: в структуре Pbcn ионы $\mathrm{Eu}^{+3}$ окружены шестью, а в структуре Pba2 - семью анионами кислорода. 
$\mathrm{B}$ спектре люминесценции $\left(\mathrm{Lu}_{1-x} \mathrm{Eu}_{x}\right)_{2}\left(\mathrm{MoO}_{4}\right)_{3}$ при $x>0.5$ наблюдается ряд новых полос, среди которых наибольшую интенсивность имеют полосы $\sim 614.4$ и $\sim 616.6 \mathrm{~nm}$. В [11] установлено, что максимальная интенсивность свечения ионов $\mathrm{Eu}^{3+}$ наблюдается для соединения $\left(\mathrm{Lu}_{0.2} \mathrm{Eu}_{0.8}\right)_{2}\left(\mathrm{MoO}_{4}\right)_{3}$ при возбуждении светом, соответствующим резонансным полосам поглощения $\left(\lambda_{\mathrm{ex}}=395\right.$ и $\left.466 \mathrm{~nm}\right)$.

Представляется целесообразным проведение исследований спектральных характеристик и кристаллической структуры твердых растворов вольфраматов $\mathrm{Lu} \mathrm{и} \mathrm{Eu}$, однотипных по строению анионов с молибдатами этих редких земель.

$\mathrm{B}$ то время как молибдат европия $\mathrm{Eu}_{2}\left(\mathrm{MoO}_{4}\right)_{3}$ имеет несколько структурных модификаций: моноклинную $\alpha$-фазу (пр.гр. $C 2 / c$ ); тетрагональную $\beta$-фазу (пр.гр. $\left.P \overline{4} 2{ }_{1} m\right)$ и орторомбическую $\beta^{\prime}$-фазу (пр.гр. Рba2) $[14,15]$, вольфрамат европия $\mathrm{Eu}_{2}\left(\mathrm{WO}_{4}\right)_{3}$, согласно исследованиям структуры вольфраматов редкоземельных ионов, выполненным в [16], имеет одну структурную модификацию - моноклинную структуру (пр.гр. C2/c). Для вольфрамата лютеция $\mathrm{Lu}_{2}\left(\mathrm{WO}_{4}\right)_{3}$ характерна также одна структурная модификация орторомбическая структура Pbcn (Pnca) [16].

$\mathrm{B}$ настоящей работе проведены исследования изменения структуры твердого раствора $\left(\mathrm{Lu}_{1-x} \mathrm{Eu}_{x}\right)_{2}\left(\mathrm{WO}_{4}\right)_{3}$ в зависимости от соотношения между концентрациями $\mathrm{Lu}$ и $\mathrm{Eu}$ при $0 \leq x \leq 1$. Установлено соответствие между структурой и спектральными характеристиками этого соединения. Определен состав, имеющий максимальную интенсивность свечения ионов $\mathrm{Eu}^{3+}$ в $\left(\mathrm{Lu}_{1-x} \mathrm{Eu}_{x}\right)_{2}\left(\mathrm{WO}_{4}\right)_{3}$.

\section{2. Методики эксперимента}

\section{1. Синтез образцов}

Исходными соединениями для синтеза вольфраматов лютеция и европия были паравольфрамат аммония $\left(\mathrm{NH}_{4}\right)_{10}\left[\mathrm{H}_{2} \mathrm{~W}_{12} \mathrm{O}_{42}\right] 4 \mathrm{H}_{2} \mathrm{O}$, оксиды $\mathrm{Lu}_{2} \mathrm{O}_{3}$ и $\mathrm{Eu}_{2} \mathrm{O}_{3}$, азотная кислота и водный аммиак. Все использованные химические вещества соответствовали квалификации „ЧДА“. Ионы $\mathrm{Lu}^{3+}$ и $\mathrm{Eu}^{3+}$ вводили в реакцию в виде водных растворов нитратных солей, полученных растворением исходных оксидов редких земель в азотной кислоте. Синтез микрокристаллических порошков вольфраматов состава $\left(\mathrm{Lu}_{1-x} \mathrm{Eu}_{x}\right)_{2}\left(\mathrm{WO}_{4}\right)_{3} \quad(0 \leq x \leq 1)$ проводился следующим образом. Стехиометрические количества паравольфрамата аммония и нитратов редких земель смешивали в воде и реакционную массу доводили до кипения, при этом суммарная концентрация ионов $\mathrm{Lu}^{3+}$ и $\mathrm{Eu}^{3+}$ в объеме $30-40 \mathrm{ml}$ составляла величину $(1.0-1.2) 10^{-4} \mathrm{~mol} / \mathrm{l}$. Далее в реакционную массу при интенсивном перемешивании добавляли водный аммиак до значения $\mathrm{pH}=8-9$. Образовавшийся гель высушивали осторожным выпариванием до образования твердого продукта, который далее отжигали в течение

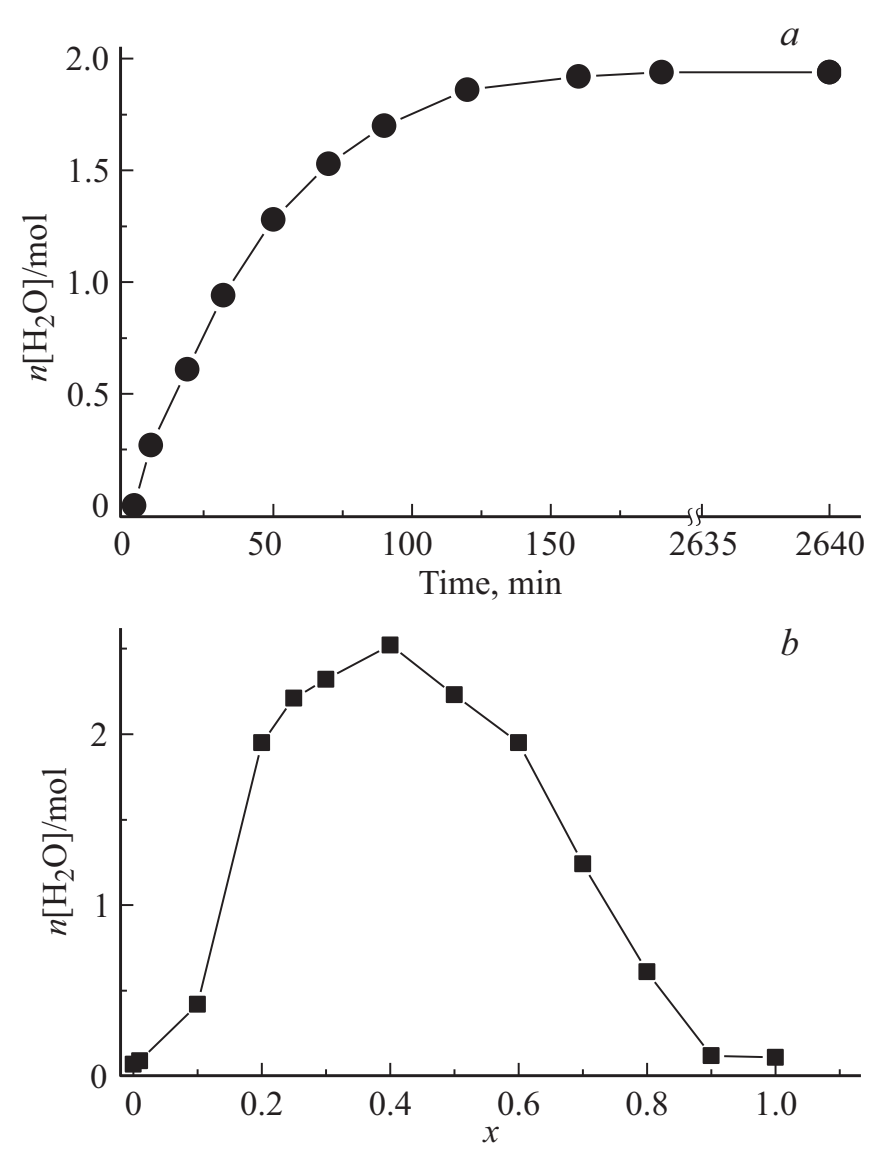

Рис. 1. Адсорбция воды вольфраматами при влажности $=45-50 \%$ и $T=18^{\circ} \mathrm{C}\left(1 \mathrm{~mol} \mathrm{H}_{2} \mathrm{O}\right.$ на $1 \mathrm{~mol}$ вольфрамата $)$. $a$ - кинетика адсорбции воды образцом $\left(\mathrm{Lu}_{0.4} \mathrm{Eu}_{0.6}\right)_{2}\left(\mathrm{WO}_{4}\right)_{3}$; $b-$ зависимость количества адсорбированной воды образцами $\left(\mathrm{Lu}_{1-x} \mathrm{Eu}_{x}\right)_{2}\left(\mathrm{WO}_{4}\right)_{3}$ от содержания $\mathrm{Eu}(x)$.

одного часа при $550^{\circ} \mathrm{C}$ для удаления остаточной влаги и разложения нитратных солей. Полученный продукт тщательно перетирали в агатовой ступке, переносили в корундовый тигель и подвергали высокотемпературному отжигу при $970^{\circ} \mathrm{C}$ в течение $2 \mathrm{~h}$. В настоящей работе исследования проводились как на обезвоженных образцах, полученных непосредственно после синтеза, так и на образцах, содержащих воду, количество которой определялось по увеличению веса образца при выдержке его на воздухе.

С целью определения скорости поглощения воды порошками вольфраматов, а также измерения количества воды, приходящегося на $1 \mathrm{~mol}$ вещества, были проведены кинетические эксперименты (рис. 1,a), а также изучена изотерма адсорбции воды соединением $\left(\mathrm{Lu}_{1-x} \mathrm{Eu}_{x}\right)_{2}\left(\mathrm{WO}_{4}\right)_{3}$ в зависимости от содержания европия (рис. $1, b$ ). Как видно из рис. $1, a$, поглощение воды вольфраматом завершается практически за 3-4 h.

Изотерма адсорбции воды порошками $\left(\mathrm{Lu}_{1-x} \mathrm{Eu}_{x}\right)_{2}\left(\mathrm{WO}_{4}\right)_{3}$ имеет сложный характер. При увеличении содержания европия до $x=0.4$ происходит увеличение количества адсорбированной воды до $2.5 \mathrm{~mol}$ $\mathrm{H}_{2} \mathrm{O}$ на $1 \mathrm{~mol}$ вольфрамата. При дальнейшем увеличении 

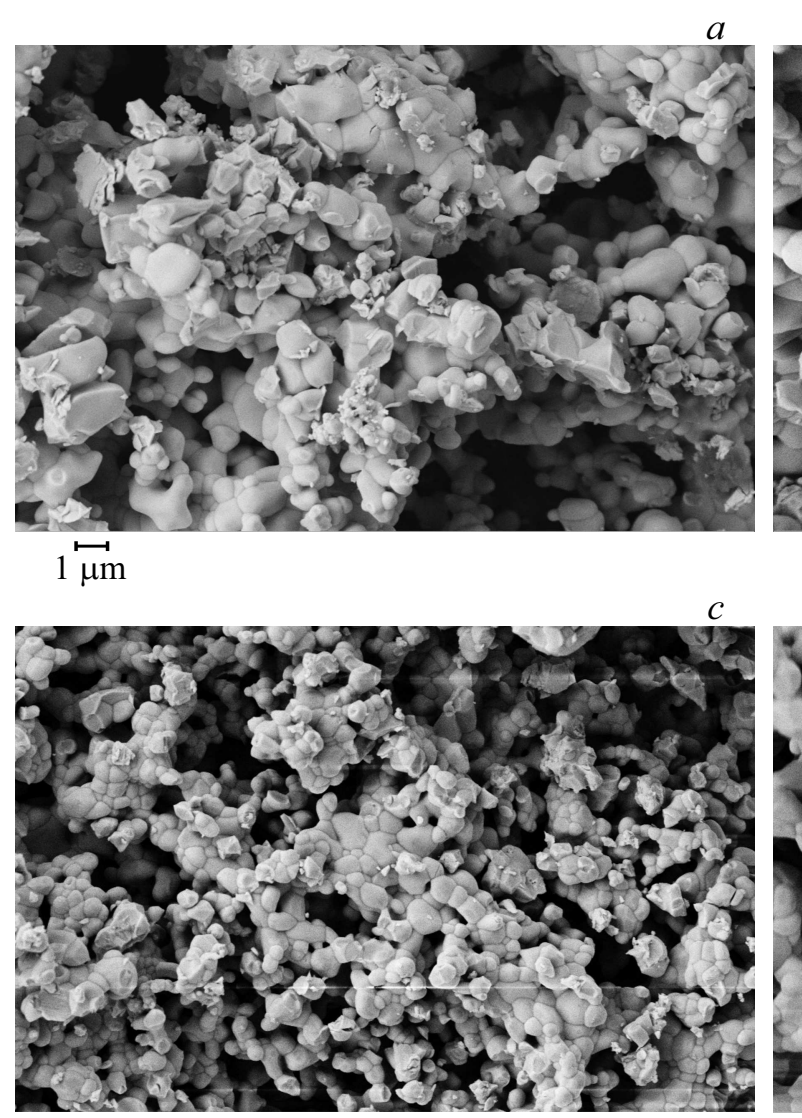

$1 \stackrel{\mathrm{m}}{\mathrm{m}}$

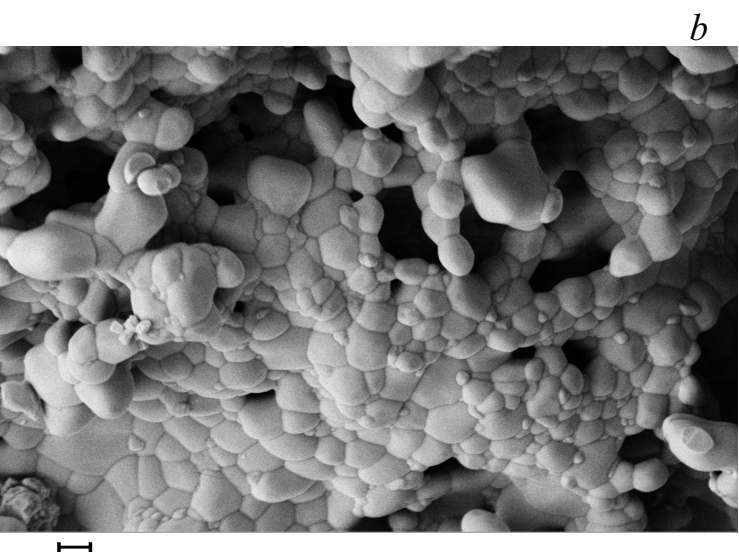

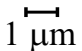

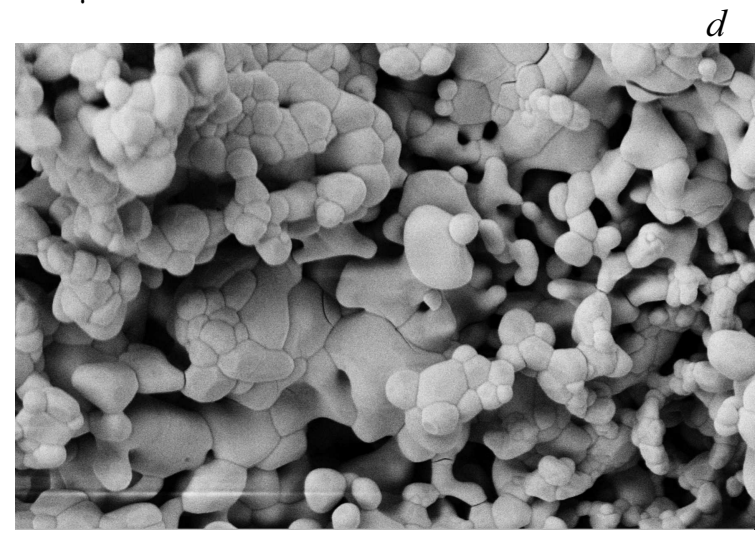

$1 \stackrel{1}{\mu \mathrm{m}}$

Рис. 2. Морфология вольфраматов $\left(\mathrm{Lu}_{1-x} \mathrm{Eu}_{x}\right)_{2}\left(\mathrm{WO}_{4}\right)_{3} . a-\mathrm{Lu}_{2}\left(\mathrm{WO}_{4}\right)_{3} ; b-\left(\mathrm{Lu}_{0.6} \mathrm{Eu}_{0.4}\right)_{2}\left(\mathrm{WO}_{4}\right)_{3} ; c-\left(\mathrm{Lu}_{0.2} \mathrm{Eu}_{0.8}\right)_{2}\left(\mathrm{WO}_{4}\right)_{3}$; $d-\mathrm{Eu}_{2}\left(\mathrm{WO}_{4}\right)_{3}$.

количества европия происходит уменьшение количества адсорбированной воды до $0.1 \mathrm{~mol}$ при $0.9 \leq x \leq 1$ (рис. $1, b)$, что связано, как показано в разд. 4 настоящей работы, с уменьшением относительного количества орторомбической фазы в образце по мере увеличения концентрации $\mathrm{Eu}$.

\section{2. Методы исследований}

Рентгенодифракционные исследования образцов полученных вольфраматов проводились с использованием дифрактометра Bruker Phaser-2 (излучение $\mathrm{CoK}$, $\lambda=1.7903 \AA$ ). Фазовый анализ образцов и расчет параметров решетки проводился с использованием программ Match и PowderCell 2.4.

ИК-спектры поглощения образцов измерялись на Фурье-спектрометре VERTEX 80v в спектральном диапазоне $400-5000 \mathrm{~cm}^{-1}$ с разрешением $2 \mathrm{~cm}^{-1}$. Для измерений образцы вольфраматов перетирались в агатовой ступке, а затем тонким слоем наносились на кристаллическую шлифованную подложку $\mathrm{KBr}$.

Морфология образцов изучалась с использованием рентгеновского микроанализатора Supra 50VP с приставкой для EDS INCA (Oxford).
Спектры люминесценции и спектры возбуждения люминесценции изучались на установке, состоящей из источника света - лампы ДКСШ-150, двух монохроматоров МДР-4 и МДР-6 (спектральный диапазон 200-1000 nm, дисперсия $1.3 \mathrm{~nm} / \mathrm{mm})$. Регистрация свечения осуществлялась фотоумножителем ФЭУ-106 (область спектральной чувствительности 200-800 nm) и усилительной системой. Монохроматор МДР-4 использовался для изучения спектров возбуждения люминесценции образцов, монохроматор МДР-6 применялся для изучения спектров люминесценции.

Спектральные и структурные характеристики, а также морфология образцов, исследовались при комнатной температуре.

\section{3. Морфология образцов}

На рис. 2 представлена морфология микрокристаллов вольфраматов $\left(\mathrm{Lu}_{1-x} \mathrm{Eu}_{x}\right)_{2}\left(\mathrm{WO}_{4}\right)_{3}$ с разным содержанием $\mathrm{Eu}(0 \leq x \leq 1)$. Как видно из рисунка, частицы имеют округлую форму. Их размер составляет $1-3 \mu \mathrm{m}$ и практически не зависит от содержания $\mathrm{Eu}$ и структурной модификации образца. Отсутствие огранки у 
микрокристаллов вольфраматов, возможно, связано с их частичным оплавлением при температуре отжига $970^{\circ} \mathrm{C}$.

\section{4. Рентгеноструктурные исследования}

Дифрактограммы порошковых образцов исследуемых вольфраматов приведены на рис. 3. Образец состава $\mathrm{Lu}_{2}\left(\mathrm{WO}_{4}\right)_{3}$ однофазный со структурой, аналогичной $\mathrm{Sc}_{2}\left(\mathrm{WO}_{4}\right)_{3}$, пр.гр. Pbcn № 60, экспериментальные значения параметров решетки: $a=13.782 \AA$, $b=9.873 \AA, c=9.961 \AA, V=1355.4 \AA^{3}$. Легированные образцы $\left(\mathrm{Lu}_{1-x} \mathrm{Eu}_{x}\right)_{2}\left(\mathrm{WO}_{4}\right)_{3}$ при $x=0.01,0.10,0.20$, $0.25,0.30$ и 0.40 - также однофазные. Образцы, полученные при составах $x=0.50,0.60$ и 0.80 , являются двухфазными: кроме фазы с орторомбической структурой $P b c n$, в них присутствует моноклинная фаза типа $\mathrm{Eu}_{2}\left(\mathrm{WO}_{4}\right)_{3}, C 2 / c$, пр. гр. № 15 (PDF 72-0504). Образцы, полученные при больших концентрациях $\mathrm{Eu}, x=0.90$, 0.99 и 1.00 , являются однофазными с упомянутой моно-

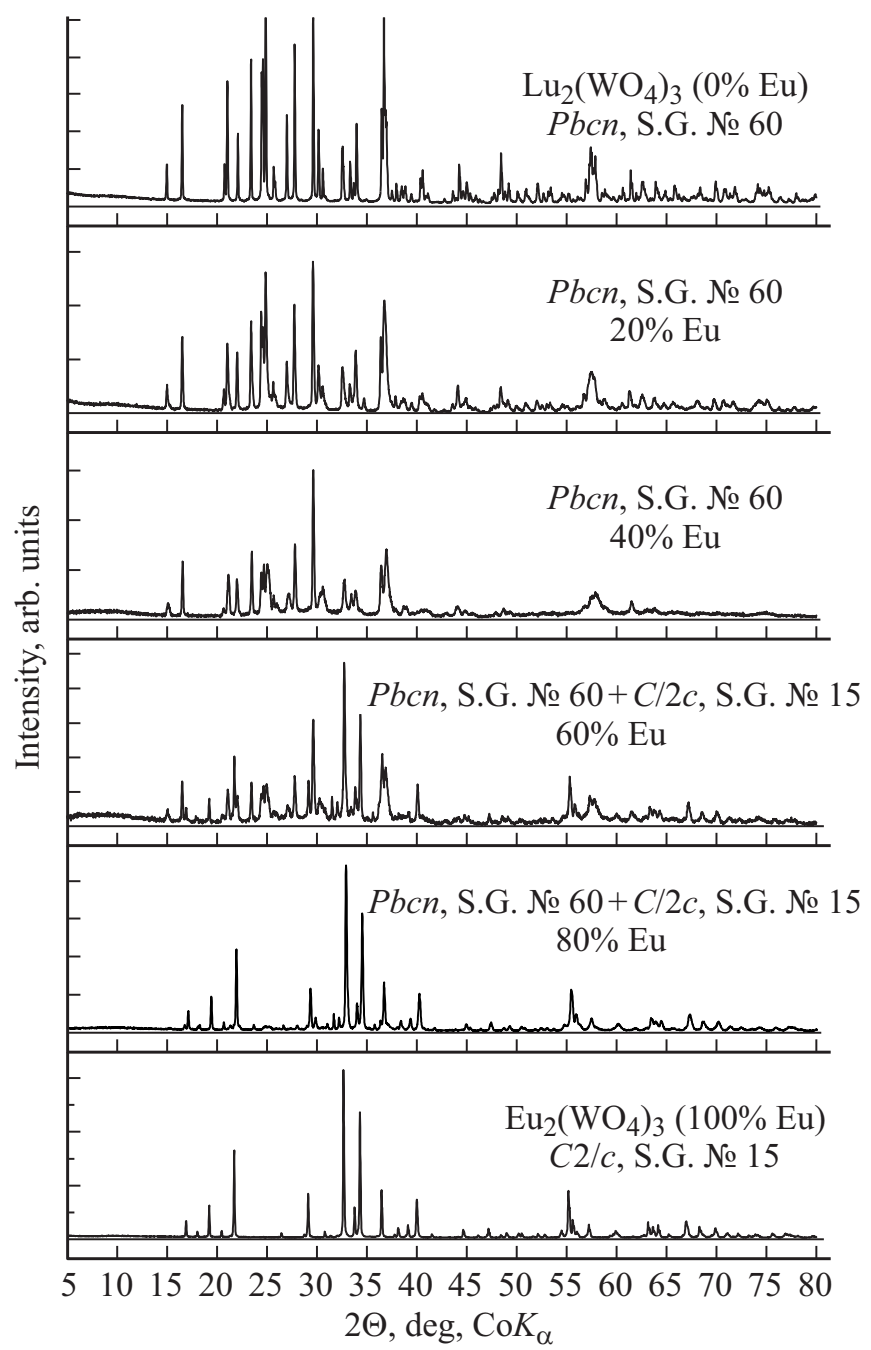

Рис. 3. Дифрактограммы вольфраматов $\left(\mathrm{Lu}_{1-x} \mathrm{Eu}_{x}\right)_{2}\left(\mathrm{WO}_{4}\right)_{3}$.

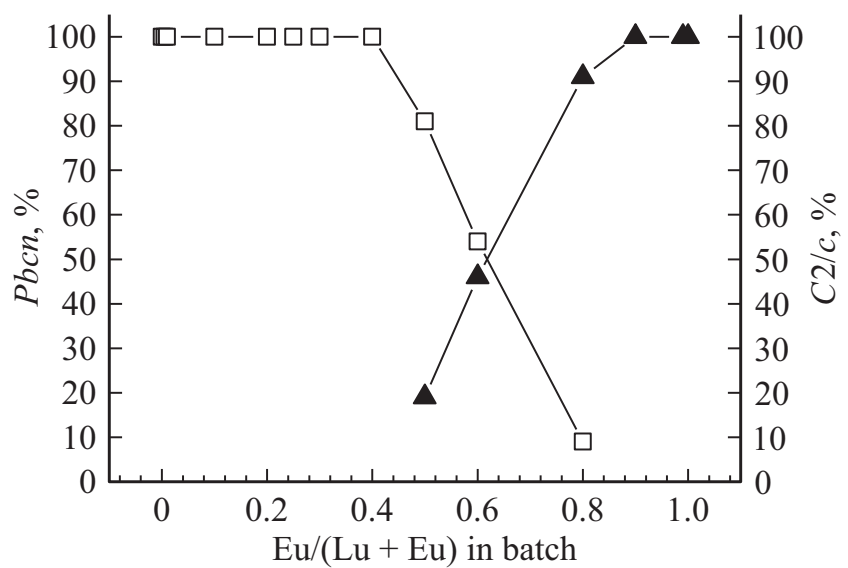

Рис. 4. Фазовый состав синтезированных образцов в зависимости от соотношения редких земель в шихте.

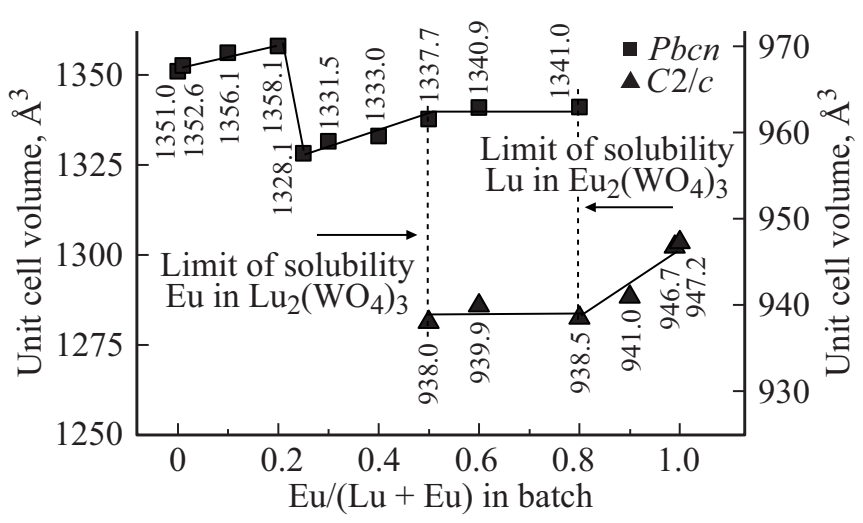

Рис. 5. Объемы элементарных ячеек фаз, $\AA^{3}$.

клинной структурой. Соответствующие изменения фазового состава отражены на рис. 4.

Ионный радиус легирующего элемента $\mathrm{Eu}^{3+}(0.950 \AA)$ больше, чем ионный радиус $\mathrm{Lu}^{3+}(0.848 \AA)$ [17]. Замещение $\mathrm{Lu}$ на $\mathrm{Eu}$ приводит к увеличению размера каналов, по которым вода может входить из атмосферы в образец, как показано в [18] для $\mathrm{Fe}_{2-x} \mathrm{Y}_{x} \mathrm{Mo}_{3} \mathrm{O}_{12}$. Предполагается, что интеркалированная вода образует водородные связи с кислородом тетраэдров, разворачивая тетраэдры определенным образом, что приводит к более плотной упаковке структуры и уменьшению объема элементарной ячейки, не приводя, однако к существенному изменению структуры орторомбической фазы, и дифракционные спектры могут быть анализированы в рамках структурной модели безводной фазы. Начиная с концентрации Еu 25\%, вхождение воды в структуру происходит быстро, так что нам не удавалось снять дифрактограммы безводных образцов. В случае чистого $\mathrm{Lu}$-образца этот процесс длительный (занимает месяцы); также для составов до $x=0.20$ это время было велико относительно времени записи дифрактограмм $(2 \mathrm{~h})$, что 
позволяло получать данные для условно безводных образцов. В существенно более плотной структуре моноклинной фазы $C 2 / c$ пространство для вхождения воды отсутствует, и эта фаза всегда безводная.

На рис. 5 приведены значения объема элементарной ячейки структуры для получающихся фаз в зависимости от относительного содержания Еu. Видно, что при $x=0.25$ происходит существенное уменьшение объема ячейки для орторомбической фазы, что связано с вхождением воды в структуру. В целом же легирование европием приводит к монотонному росту объема ячейки, как в обезвоженных, так и в не обезвоженных структурах орторомбической фазы. В двухфазной области, внутри пределов растворимости, объемы элементарной ячейки структуры обеих фаз постоянны, следовательно, постоянны и составы $\left(\mathrm{Lu}_{1-x} \mathrm{Eu}_{x}\right)_{2}\left(\mathrm{WO}_{4}\right)_{3}$ для обеих фаз, несмотря на изменение концентрации легирующих элементов. „Избыточная“ концентрация выбирается за счет изменения относительного количества фаз в образце. За пределом растворимости в моноклинной фазе снова наблюдается монотонный рост объема элементарной ячейки структуры с увеличением содержания $\mathrm{Eu}$.

Таким образом, внутри пределов растворимости при $x=0.50-0.80$ обе фазы являются твердыми растворами с постоянным составом: орторомбическая фаза - $\left(\mathrm{Lu}_{0.5} \mathrm{Eu}_{0.5}\right)_{2}\left(\mathrm{WO}_{4}\right)_{3}$, а моноклинная фаза - примерно $\left(\mathrm{Lu}_{0.2} \mathrm{Eu}_{0.8}\right)_{2}\left(\mathrm{WO}_{4}\right)_{3}$. Аналогичные зависимости наблюдались нами ранее при изучении молибдатов $\left(\mathrm{Lu}_{1-x} \mathrm{Eu}_{x}\right)_{2}\left(\mathrm{MoO}_{4}\right)_{3}[11]$.

\section{5. Результаты ИК-спектроскопии}

Структурные исследования показали, что соединения $\mathrm{Lu}_{2}\left(\mathrm{WO}_{4}\right)_{3}$ и $\mathrm{Eu}_{2}\left(\mathrm{WO}_{4}\right)_{3}$ имеют орторомбическую структуру (пр.гр. № 60, Pbcn) и моноклинную (пр. гр. № 15, $C 2 / c$ ) соответственно. В обеих структурах атом вольфрама имеет тетраэдрическое окружение атомами кислорода.

Для тетраэдрической изолированной молекулы $\mathrm{WO}_{4}$ симметрии $T_{d}$ в колебательном спектре возможны четыре типа нормальных колебаний: $v_{1}$ - валентное симметричное колебание связи $\mathrm{W}-\mathrm{O}\left(A_{1}\right), v_{2}$ - деформационное валентное колебание $\mathrm{W}-\mathrm{O}(E), v_{3}$ и $v_{4}-$ валентное асимметричное $\left(F_{2}\right)$ и деформационное асимметричное $\left(F_{2}\right)$ колебания $\mathrm{W}-\mathrm{O}$ соответственно. Из них в ИК-спектре активны только колебания $v_{3}$ и $v_{4}$ Для свободного иона $\mathrm{WO}_{4}^{2-}$ частоты этих колебаний равны 833 и $405 \mathrm{~cm}^{-1}$ [19].

Орторомбическая Pbcn-структура $\mathrm{Lu}_{2}\left(\mathrm{WO}_{4}\right)_{3}$ и моноклинная $C 2 / c$-структура $\mathrm{Eu}_{2}\left(\mathrm{WO}_{4}\right)_{3}$ имеют 2 кристаллографически различные позиции для тетраэдрически координированного атома вольфрама. Тетраэдр $\mathrm{W}^{1} \mathrm{O}_{4}$ имеет симметрию $C_{2}$, близкую к геометрически правильному тетраэдру, а $\mathrm{W}^{2} \mathrm{O}_{4}$, более искаженный, $-C_{1}$. Понижение позиционной симметрии аниона $\mathrm{WO}_{4}^{2-}$ при переходе к кристаллу приводит к тому, что при этом

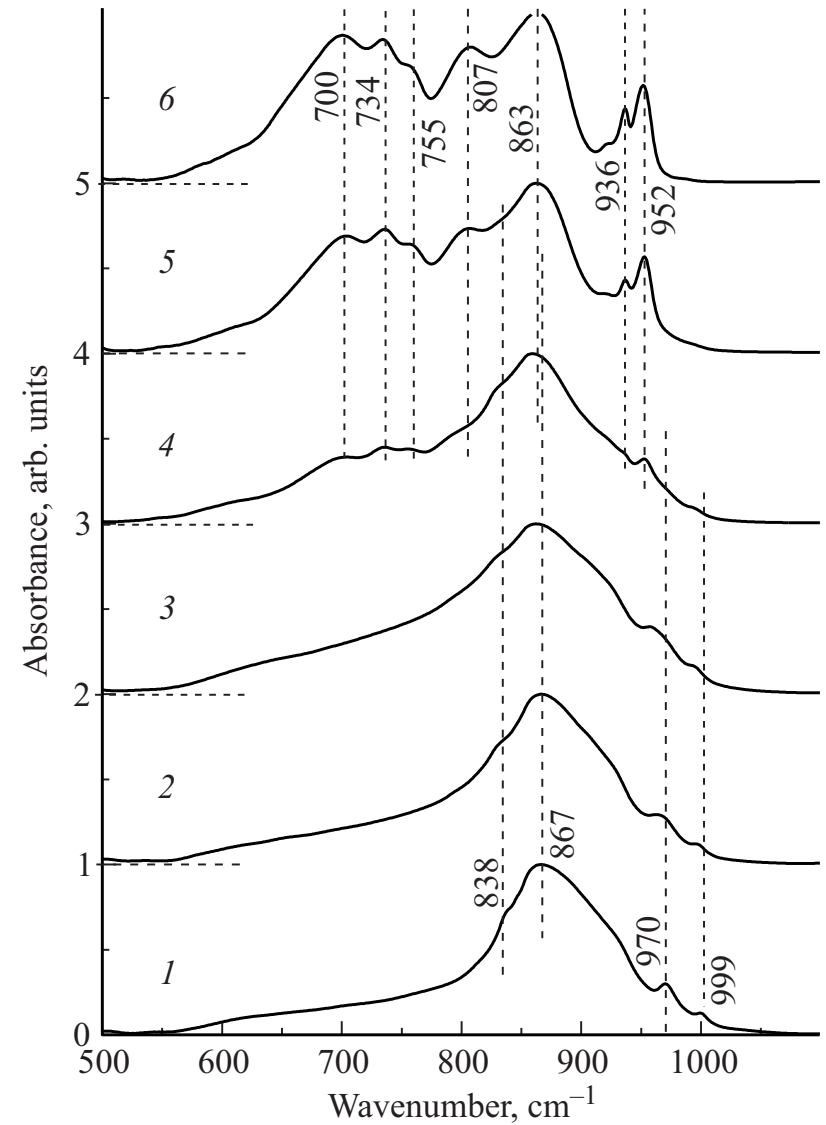

Рис. 6. ИК-спектры поглощения обезвоженных вольфраматов $\left(\mathrm{Lu}_{1-x} \mathrm{Eu}_{x}\right)_{2}\left(\mathrm{WO}_{4}\right)_{3} .1-\mathrm{Lu}_{2}\left(\mathrm{WO}_{4}\right)_{3} ; 2-\left(\mathrm{Lu}_{0.8} \mathrm{Eu}_{0.2}\right)_{2}\left(\mathrm{WO}_{4}\right)_{3}$; $3-\left(\mathrm{Lu}_{0.6} \mathrm{Eu}_{0.4}\right)_{2}\left(\mathrm{WO}_{4}\right)_{3} ; 4-\left(\mathrm{Lu}_{0.4} \mathrm{Eu}_{0.6}\right)_{2}\left(\mathrm{WO}_{4}\right)_{3}$; $5-\left(\mathrm{Lu}_{0.2} \mathrm{Eu}_{0.8}\right)_{2}\left(\mathrm{WO}_{4}\right)_{3} ; 6-\mathrm{Eu}_{2}\left(\mathrm{WO}_{4}\right)_{3}$.

становится активным колебание $v_{1}(A)$, полностью снимается вырождение колебаний $v_{2}(2 A), v_{3}$ и $v_{4}(A+2 B$ или $3 A$ для $C_{2}$ и $C_{1}$ соответственно), что приводит к расщеплению колебательных полос. Переход от представлений позиционных групп симметрии к представлениям фактор-групп пространственных групп кристаллов $D_{2 h}$ $(P b c n)$ и $C_{2 h}(C 2 / c)$ приводит к дополнительному расщеплению и увеличению числа колебательных полос в ИК-спектре [20,21].

На рис. 6 в спектральном диапазоне $500-1100 \mathrm{~cm}^{-1}$ приведены спектры поглощения (1-6) обезвоженных образцов соединений $\left(\mathrm{Lu}_{1-x} \mathrm{Eu}_{x}\right)_{2}\left(\mathrm{WO}_{4}\right)_{3}(x=0,0.2,0.4$, $0.6,0.8,1) . \mathrm{B} \mathrm{Lu}_{2}\left(\mathrm{WO}_{4}\right)_{3}$ (спектр 1) наблюдается широкая интенсивная линия поглощения $\sim 867 \mathrm{~cm}^{-1}$ с плечом $\sim 838 \mathrm{~cm}^{-1}$. На правом крыле этой линии наблюдаются две линии малой интенсивности, 970 и $999 \mathrm{~cm}^{-1}$. Следуя [22,23], где представлены ИК-спектры изоструктурных соединений $\mathrm{Sc}_{2}\left(\mathrm{WO}_{4}\right)_{3}, \mathrm{In}_{2}\left(\mathrm{WO}_{4}\right)_{3}, \mathrm{Al}_{2}\left(\mathrm{WO}_{4}\right)_{3}$ c орторомбической структурой $P b c n$, мы можем отнести линии поглощения 867 и $838 \mathrm{~cm}^{-1}$ в спектре $\mathrm{Lu}_{2}\left(\mathrm{WO}_{4}\right)_{3}$ к асимметричным валентным колебаниям $v_{3}$, а линии 970 и $999 \mathrm{~cm}^{-1}$ - к симметричным валентным колебаниям $v_{1}$. 
В спектрах $\left(\mathrm{Lu}_{1-x} \mathrm{Eu}_{x}\right)_{2}\left(\mathrm{WO}_{4}\right)_{3}(x=0.2,0.4$, рис. 6 , спектры 2 и 3) наблюдаются незначительные изменения: уширяется линия $867 \mathrm{~cm}^{-1}$, сглаживается плечо $838 \mathrm{~cm}^{-1}$, линии колебаний $v_{1}$ уширяются и незначительно смещаются в низкоэнергетическую область. При этом форма спектра не меняется, свидетельствуя в пользу того, что образцы с $x=0.2$ и 0.4 имеют орторомбическую структуру. Это согласуется с рентгеновскими результатами.

Дальнейшее увеличение концентрации $\mathrm{Eu}$ в $\left(\mathrm{Lu}_{1-x} \mathrm{Eu}_{x}\right)_{2}\left(\mathrm{WO}_{4}\right)_{3}$ до $x=0.6$ (рис. 6, спектр 4) приводит к исчезновению линий 970 и $999 \mathrm{~cm}^{-1}$ и появлению в спектре $\left(\mathrm{Lu}_{0.4} \mathrm{Eu}_{0.6}\right)_{2}\left(\mathrm{WO}_{4}\right)_{3}$ новых линий $-700,734$, $755,807,936$ и $952 \mathrm{~cm}^{-1}$. Плечо $838 \mathrm{~cm}^{-1}$ на фоне линии поглощения $863 \mathrm{~cm}^{-1}$ сохраняется. По данным рентгеновского анализа, образец с таким составом содержит две структуры: орторомбическую $P b c n$ и моноклинную $C 2 / c$, т.е. является двухфазным. Интенсивность новых линий увеличивается в спектрах с $x=0.8$ и $x=1$ (рис. 6, спектры 5 и 6), а линия поглощения $838 \mathrm{~cm}^{-1}$ исчезает. По данным рентгенофазового анализа образец $\left(\mathrm{Lu}_{0.2} \mathrm{Eu}_{0.8}\right)_{2}\left(\mathrm{WO}_{4}\right)_{3} \quad$ является также двухфазным. Отсутствие в ИК-спектре образца $\left(\mathrm{Lu}_{02} \mathrm{Eu}_{0.8}\right)_{2}\left(\mathrm{WO}_{4}\right)_{3}$ линий орторомбической фазы $P b c n$ может быть связано как с ее малым количеством, так и с тем, что самая интенсивная линия $\sim 860 \mathrm{~cm}^{-1}$ в фазах $P b c n$ и $C 2 / c$ имеет практически одинаковое спектральное положение.

Образец $\mathrm{Eu}_{2}\left(\mathrm{WO}_{4}\right)_{3}$ - однофазный и имеет моноклинную структуру $C 2 / c$. Его спектр (рис. 6, спектр 6) подобен спектру наночастиц $\mathrm{Eu}_{2}\left(\mathrm{WO}_{4}\right)_{3}$ [24] и спектрам изоструктурных соединений $\mathrm{Ce}_{2}\left(\mathrm{WO}_{4}\right)_{3}$ и $\mathrm{La}_{2}\left(\mathrm{WO}_{4}\right)_{3}$ [21] с моноклинной структурой $C 2 / c$. В соответствии с [21] наблюдаемые в спектре линии поглощения могут быть отнесены к валентным колебаниям группы $\mathrm{WO}_{4}$ : асимметричным $v_{3}(700,734,755,807$, $863 \mathrm{~cm}^{-1}$ ) и симметричным $v_{1}\left(936\right.$ и $952 \mathrm{~cm}^{-1}$ ).

Таким образом, исследование ИК-спектров в области внутренних валентных колебаний тетраэдра $\mathrm{WO}_{4}$ показало, что в результате увеличения концентрации $\mathrm{Eu}$ в соединении $\left(\mathrm{Lu}_{1-x} \mathrm{Eu}_{x}\right)_{2}\left(\mathrm{WO}_{4}\right)_{3}$ наблюдается переход исходного соединения $\mathrm{Lu}_{2}\left(\mathrm{WO}_{4}\right)_{3}$ с орторомбической структурой $P b c n$ в соединение $\mathrm{Eu}_{2}\left(\mathrm{WO}_{4}\right)_{3}$ с моноклинной структурой $C 2 / c$.

Заметим, что практически во всех спектрах обезвоженных образцов наблюдались слабые линии поглощения, обусловленные колебаниями связей $\mathrm{O}-\mathrm{H}$ молекул воды. В [25] было отмечено, что редкоземельные вольфраматы и молибдаты структурного типа $\mathrm{Sc}_{2}\left(\mathrm{WO}_{4}\right)_{3}$, т.е. с орторомбической решеткой $P b c n$, вследствие рыхлости структуры являются гигроскопичными материалами. Нами были проведены измерения ИК-спектров $\left(\mathrm{Lu}_{1-x} \mathrm{Eu}_{x}\right)_{2}\left(\mathrm{WO}_{4}\right)_{3} \quad(x=0,0.2,0.3,0.4)$ с орторомбической структурой не обезвоженных образцов, которые находились на воздухе $(T=300 \mathrm{~K}$, влажность $\psi=50 \%)$ в течение $2-14$ суток. В спектрах пропускания этих образцов также присутствовали линии поглощения $\sim 3400 \mathrm{~cm}^{-1}$ и $\sim 1640 \mathrm{~cm}^{-1}$, обусловленные

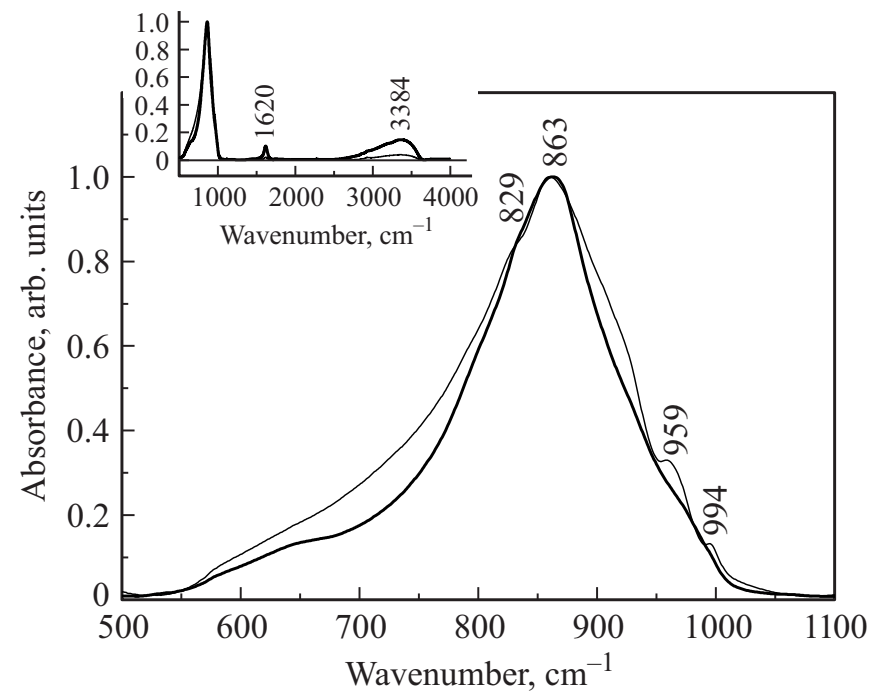

Рис. 7. ИК-спектры поглощения обезвоженного (тонкая кривая) и не обезвоженного (толстая кривая) вольфрамата $\left(\mathrm{Lu}_{0.7} \mathrm{Eu}_{0.3}\right)_{2}\left(\mathrm{WO}_{4}\right)_{3}$. На вставке - спектры в широком диапазоне $500-4000 \mathrm{~cm}^{-1}$, спектры нормированы к максимальной величине.

валентными и деформационными колебаниями связи $\mathrm{O}-\mathrm{H}$ молекул воды. В области внутримолекулярных валентных колебаний связи $\mathrm{W}-\mathrm{O}$ спектр поглощения $\mathrm{Lu}_{2}\left(\mathrm{WO}_{4}\right)_{3}$ не обезвоженного образца был идентичен спектру обезвоженного образца. В нем наблюдались линии поглощения асимметричных колебаний $v_{3}$ и симметричных $v_{1}$ (рис. 6, спектр 1). Однако в спектрах не обезвоженных образцов $\left(\mathrm{Lu}_{1-x} \mathrm{Eu}_{x}\right)_{2}\left(\mathrm{WO}_{4}\right)_{3} \mathrm{c}$ $x=0.2,0.3,0.4$ линий поглощения колебаний $v_{1}$ не наблюдалось. В качестве примера на рис. 7 приведены спектры поглощения $\left(\mathrm{Lu}_{0.7} \mathrm{Eu}_{0.3}\right)_{2}\left(\mathrm{WO}_{4}\right)_{3}$ обезвоженного (тонкая линия) и не обезвоженного (толстая линия) образцов. Обезвоженный образец был рентгенографически однофазным. Из рисунка видно, что в области внутренних валентных колебаний $\mathrm{WO}_{4}^{2-}$ спектр обезвоженного образца этого состава подобен спектрам обезвоженных орторомбических образцов других составов с $x=0,0.2,0.4$ (рис. 6 , спектры 1,2,3). В спектре не обезвоженного образца $\left(\mathrm{Lu}_{0.7} \mathrm{Eu}_{0.3}\right)_{2}\left(\mathrm{WO}_{4}\right)_{3}$ линий поглощения 970 и $999 \mathrm{~cm}^{-1}$, обусловленных симметричными валентными колебаниями $v_{1}$, не наблюдается (рис. 7, толстая линия). Интенсивность линий поглощения воды $\sim 3400 \mathrm{~cm}^{-1}$ и $\sim 1640 \mathrm{~cm}^{-1}$ увеличивается по сравнению с обезвоженным образцом (рис. 7, вставка, толстая и тонкая линии).

Влияние воды на спектры комбинационного рассеяния наблюдалось при исследовании соединений $\mathrm{Fe}_{2-x} \mathrm{Y}_{x} \mathrm{Mo}_{3} \mathrm{O}_{12} \quad(x=0.2-1.8)$ [18]. Было установлено, что орторомбические материалы с $x \geq 0.5$ являются гигроскопичными, при этом вода может быть представлена в двух видах - адсорбированная на поверхности и локализованная в микроканалах орторомбической структуры. Первый вид не оказывает влияния на дви- 
жение полиэдров, тогда как второй взаимодействует с полиэдрами, препятствуя не только либрационному и трансляционному движению тетраэдра $\mathrm{MO}_{4}$, но и его внутренним валентным колебаниям. Так, в спектрах комбинационного рассеяния $\mathrm{Fe}_{2-x} \mathrm{Y}_{x} \mathrm{Mo}_{3} \mathrm{O}_{12}$ с $x \geq 1$ в области валентных колебаний $v_{3}$ узкая интенсивная линия $\sim 780 \mathrm{~cm}^{-1}$ уширяется и ее интенсивность уменьшается, симметричное колебание $v_{1}$ с частотой $\sim 970 \mathrm{~cm}^{-1}$ сдвигается в область более низких энергий.

Таким образом, изменения, наблюдаемые в ИК-спектpax поглощения в области внутренних валентных колебаний тетраэдра $\mathrm{WO}_{4}$ не обезвоженных образцов $\left(\mathrm{Lu}_{1-x} \mathrm{Eu}_{x}\right)_{2}\left(\mathrm{WO}_{4}\right)_{3}$ с $x=0.2,0.3,0.4$ указывают на присутствие воды в микроканалах орторомбической структуры. Наличие воды в обезвоженных образцах обусловлено ее адсорбцией на поверхности в процессе подготовки образца к ИК-измерению.

\section{6. Спектры люминесценции и спектры возбуждения люминесценции}

\section{1. Спектры люминесценции}

Наиболее интенсивные полосы свечения в твердых растворах $\left(\mathrm{Lu}_{1-x} \mathrm{Eu}_{x}\right)_{2}\left(\mathrm{WO}_{4}\right)_{3}$, наблюдаются в диапазоне длин волн $605-630 \mathrm{~nm}$, (электронный переход $\left.{ }^{5} \mathrm{D}_{0} \rightarrow{ }^{7} \mathrm{~F}_{2}\right)$, так же как и $\left(\mathrm{Lu}_{1-x} \mathrm{Eu}_{x}\right)_{2}\left(\mathrm{MoO}_{4}\right)_{3} \quad$ [11]. На рис. 8 и 9 представлены спектры люминесценции (СЛ) образцов $\left(\mathrm{Lu}_{1-x} \mathrm{Eu}_{x}\right)_{2}\left(\mathrm{WO}_{4}\right)_{3}(0.01 \leq x \leq 1)$, обезвоженных и после пребывания их в течение 3 суток на воздухе при влажности 50-55\% соответственно. Как следует из рис. 8 и 9, изменение концентрации $\mathrm{Eu}$ приводит к существенным изменениям СЛ.

Для обезвоженных образцов (рис. 8, спектры 1-7) можно выделить 3 интервала концентраций $\mathrm{Eu}$, в которых спектр свечения остается практически неизменным при возбуждении в резонансной полосе $\mathrm{Eu}^{3+}$ $\left(\lambda_{\mathrm{ex}} \sim 395 \mathrm{~nm}\right)$, соответствующей электронному переходу ${ }^{7} \mathrm{~F}_{0} \rightarrow{ }^{5} \mathrm{~L}_{6}$ :

1. При $0.01 \leq x<0.5$ в СЛ наибольшую интенсивность имеют две полосы с $\lambda_{\max } \sim 608.4$ и $612.4 \mathrm{~nm}$ (рис. 8, спектры 1,2).

2. При $0.5 \leq x \leq 0.7$ наряду с наиболее интенсивными полосами с $\lambda_{\max } \sim 613.2$ и $615.7 \mathrm{~nm}$ наблюдаются слабые полосы с $\lambda_{\max } \sim 608.4$ и $612.4 \mathrm{~nm}$ (рис. 8, спектр 4).

3. При $0.7<x \leq 1$ в СЛ наиболее интенсивными являются полосы с $\lambda_{\max } \sim 613.2$ и $615.7 \mathrm{~nm}$ (рис. 8, спектры 5-7).

Для не обезвоженных образцов (рис. 9, спектры 1-7) СЛ $\mathrm{Eu}^{3+}$ при возбуждении светом с $\lambda_{\max } \sim 395 \mathrm{~nm}$ практически совпадает со СЛ обезвоженных образцов при концентрациях $\mathrm{Eu}^{3+} 0.5 \leq x \leq 1$. При $0.01 \leq x<0.1$ в СЛ наблюдается две полосы с $\lambda_{\max } \sim 608.4$ и $612.4 \mathrm{~nm}$, совпадающие со спектром обезвоженных образцов при $0.01 \leq x<0.5$. В области концентраций $\mathrm{Eu} 0.1 \leq x<0.5$, кроме полос с $\lambda_{\max } \sim 608.4$

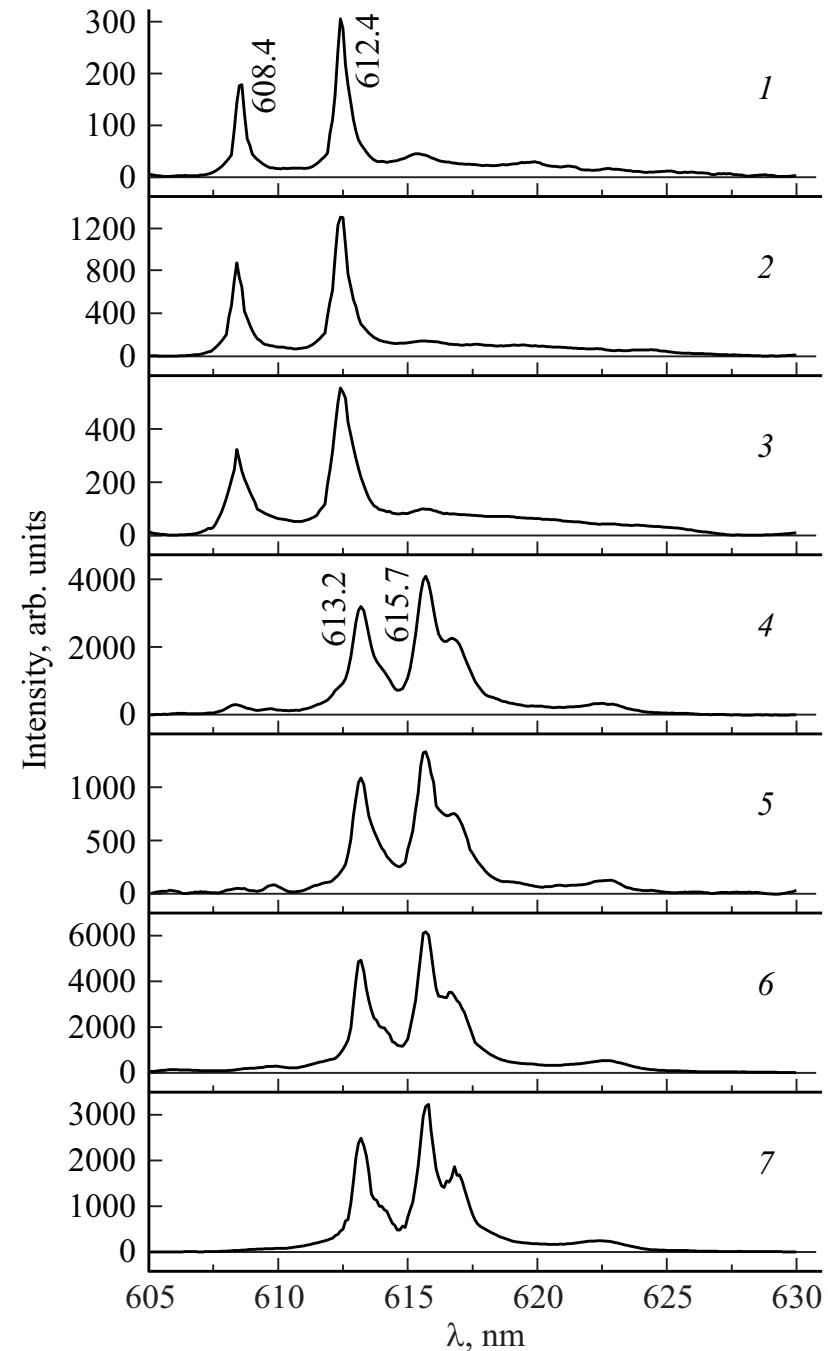

Рис. 8. Спектры люминесценции обезвоженных вольфраматов $\left(\mathrm{Lu}_{1-x} \mathrm{Eu}_{x}\right)_{2}\left(\mathrm{WO}_{4}\right)_{3} .1-\left(\mathrm{Lu}_{0.99} \mathrm{Eu}_{0.01}\right)_{2}\left(\mathrm{WO}_{4}\right)_{3}$; $2-\left(\mathrm{Lu}_{0.9} \mathrm{Eu}_{0.1}\right)_{2}\left(\mathrm{WO}_{4}\right)_{3} ; \quad 3-\left(\mathrm{Lu}_{0.9} \mathrm{Eu}_{0.1}\right)_{2}\left(\mathrm{WO}_{4}\right)_{3}$; $4-\left(\mathrm{Lu}_{0.5} \mathrm{Eu}_{0.5}\right)_{2}\left(\mathrm{WO}_{4}\right)_{3} ; \quad 5-\left(\mathrm{Lu}_{0.5} \mathrm{Eu}_{0.5}\right)_{2}\left(\mathrm{WO}_{4}\right)_{3}$; $6-\left(\mathrm{Lu}_{0.1} \mathrm{Eu}_{0.9}\right)_{2}\left(\mathrm{WO}_{4}\right)_{3} ; 7-\mathrm{Eu}_{2}\left(\mathrm{WO}_{4}\right)_{3} ; \quad(1,2,4,6$ и $\left.7-\lambda_{\mathrm{ex}}=395 \mathrm{~nm} ; 3-\lambda_{\mathrm{ex}}=252 \mathrm{~nm} ; 5-\lambda_{\mathrm{ex}}=275 \mathrm{~nm}\right)$.

и $612.4 \mathrm{~nm}$, имеющих наибольшую интенсивность, на длинноволновом спаде полосы $612.4 \mathrm{~nm}$ появляется интенсивное плечо (рис. 9, спектр 2).

Следует отметить, что спектры люминесценции обезвоженных образцов $\left(\mathrm{Lu}_{1-x} \mathrm{Eu}_{x}\right)_{2}\left(\mathrm{WO}_{4}\right)_{3}$ во всем исследованном интервале значений $0.01 \leq x \leq 1$ не зависят от длины волны возбуждающего света. При возбуждении приповерхностного слоя этих микрокристаллов светом в коротковолновой области спектра (полосе с переносом заряда, ППЗ) с $\lambda_{\text {ex }} \sim 250,272-276 \mathrm{~nm}$ и в максимуме резонансного возбуждения ионов $\mathrm{Eu}^{3+} \lambda_{\mathrm{ex}}=395 \mathrm{~nm}$ (при возбуждении всего объема) наблюдаются одни и те же спектры свечения. В качестве примера, на рис. 8 (спектры 2 и 3, 4 и 5) приведены спектры люминесценции обезвоженных образцов при возбуждении в полосе с переносом заряда и при резонансном возбуждении. 


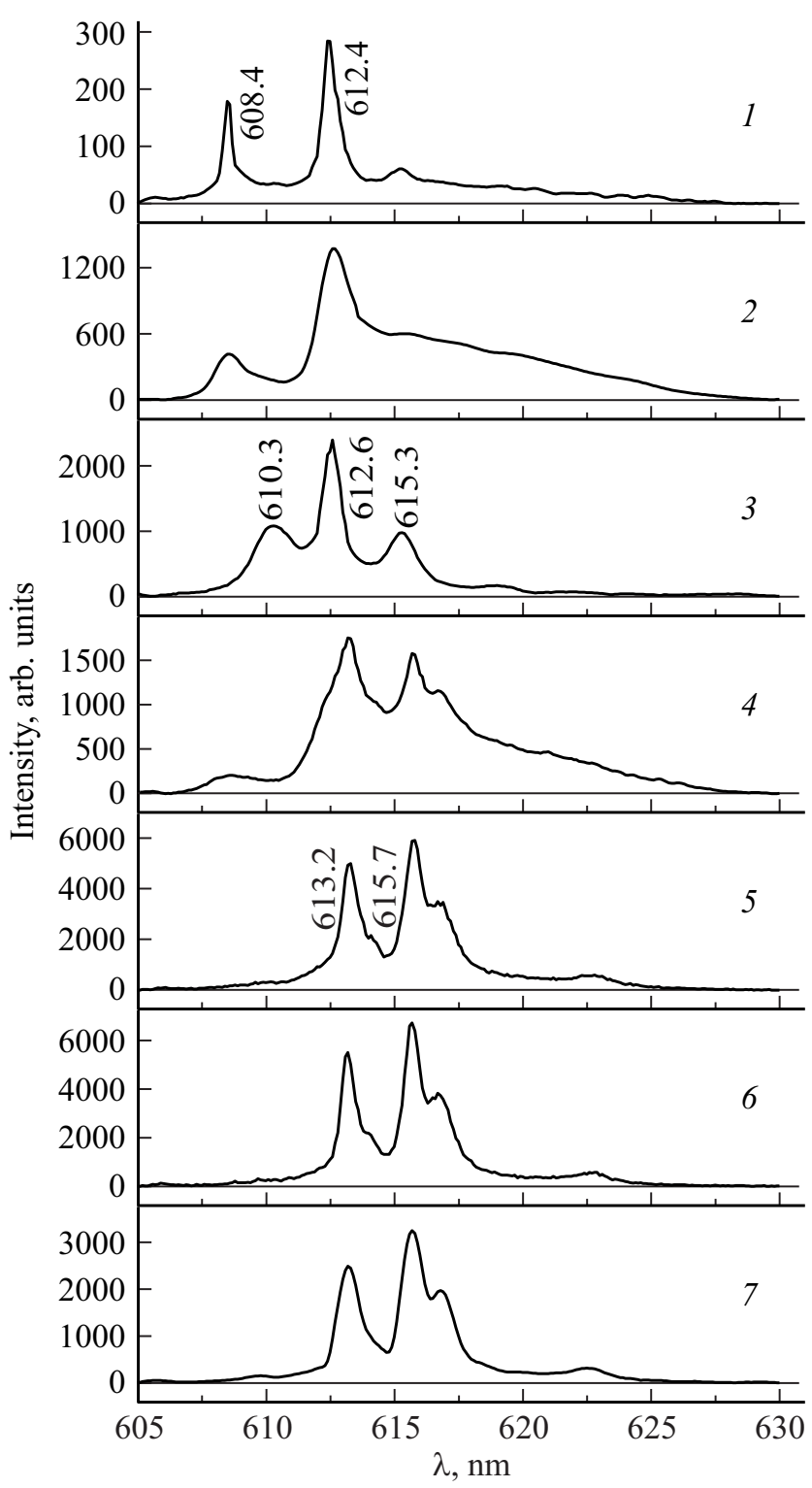

Pис. 9. Спектры люминесценции не обезвоженных вольфраматов $\left(\mathrm{Lu}_{1-x} \mathrm{Eu}_{x}\right)_{2}\left(\mathrm{WO}_{4}\right)_{3} .1-\left(\mathrm{Lu}_{0.99} \mathrm{Eu}_{0.01}\right)_{2}\left(\mathrm{WO}_{4}\right)_{3}$; $2-\left(\mathrm{Lu}_{0.8} \mathrm{Eu}_{0.2}\right)_{2}\left(\mathrm{WO}_{4}\right)_{3} ; \quad 3-\left(\mathrm{Lu}_{0.8} \mathrm{Eu}_{0.2}\right)_{2}\left(\mathrm{WO}_{4}\right)_{3}$; $4-\left(\mathrm{Lu}_{0.5} \mathrm{Eu}_{0.5}\right)_{2}\left(\mathrm{WO}_{4}\right)_{3} ; \quad 5-\left(\mathrm{Lu}_{0.2} \mathrm{Eu}_{0.8}\right)_{2}\left(\mathrm{WO}_{4}\right)_{3}$; $6-\left(\mathrm{Lu}_{0.1} \mathrm{Eu}_{0.9}\right)_{2}\left(\mathrm{WO}_{4}\right)_{3} ; 7-\mathrm{Eu}_{2}\left(\mathrm{WO}_{4}\right)_{3} .\left(3-\lambda_{\mathrm{ex}}=252 \mathrm{~nm}\right.$. Для всех других спектров люминесценции $\lambda_{\mathrm{ex}}=395 \mathrm{~nm}$.)

Спектры люминесценции не обезвоженных соединений $\left(\mathrm{Lu}_{1-x} \mathrm{Eu}_{x}\right)_{2}\left(\mathrm{WO}_{4}\right)_{3}$ при $0.5 \leq x \leq 1$ также не зависят от длины волны возбуждающего света. В то же время, в области концентраций Еu $0.01 \leq x<0.5$ при возбуждении поверхности образца и его объема СЛ отличаются. При возбуждении в ППЗ $\left(\lambda_{\text {ex }} \sim 306 \mathrm{~nm}\right)$ в СЛ наблюдаются полосы с $\lambda_{\max } \sim 610.3,612.6$ и $615.3 \mathrm{~nm}$ (рис. 9, спектр 3), тогда как при возбуждении объема образца $\left(\lambda_{\mathrm{ex}} \sim 395 \mathrm{~nm}\right)$ СЛ содержит две полосы с $\lambda_{\max } \sim 608.4$ и $612.4 \mathrm{~nm}$, а также интенсивное плечо на длинноволновом спаде полосы $612.4 \mathrm{~nm}$ (рис. 9, спектр 2).
При сопоставлении результатов спектральных исследований и рентгенофазового анализа обезвоженных вольфраматов $\left(\mathrm{Lu}_{1-x} \mathrm{Eu}_{x}\right)_{2}\left(\mathrm{WO}_{4}\right)_{3}$ наблюдается соответствие между структурным состоянием и спектральными характеристиками исследованных образцов (табл. 1). Действительно, при $0.01 \leq x<0.5$ твердый раствор $\left(\mathrm{Lu}_{1-x} \mathrm{Eu}_{x}\right)_{2}\left(\mathrm{WO}_{4}\right)_{3}$ имеет орторомбическую структуру $P b c n$. В СЛ этого соединения наибольшую интенсивность имеют две полосы с $\lambda_{\max } \sim 608.4$ и $612.4 \mathrm{~nm}$. Следует особо подчеркнуть, что практически такие же полосы $(\sim 608.3$ и $612.4 \mathrm{~nm})$ наблюдались для исследованной нами ранее орторомбической структуры $P b c n$ твердого раствора $\left(\mathrm{Lu}_{1-x} \mathrm{Eu}_{x}\right)_{2}\left(\mathrm{MoO}_{4}\right)_{3}[11]$.

При $x=0.5$ в обезвоженном соединении $\left(\mathrm{Lu}_{0.5} \mathrm{Eu}_{0.5}\right)_{2}\left(\mathrm{WO}_{4}\right)_{3}$ наряду с орторомбической структурой $P b c n$ образуется моноклинная фаза $C 2 / c$. $\mathrm{B}$ орторомбической фазе оптически активный ион $\mathrm{Eu}^{3+}$ окружен шестью анионами кислорода [13], тогда как в моноклинной $C 2 / c$-структуре ион $\mathrm{Eu}^{3+}$ окружен восемью анионами кислорода [21]. Изменение локального окружения вокруг иона $\mathrm{Eu}^{3+}$ приводит к существенным изменениям СЛ. Наибольшую интенсивность в спектре этого образца имеют полосы с $\lambda_{\max } \sim 613.2$ и $615.7 \mathrm{~nm}$, характерные для моноклинной фазы. Наряду с этими полосами наблюдаются также слабые полосы, соответствующие орторомбической фазе. При увеличении концентрации $\mathrm{Eu}$ количество моноклинной фазы возрастает, и при $0.8 \leq x \leq 1$ твердый раствор имеет моноклинную структуру $C 2 / c$. В СЛ этих образцов наблюдаются только полосы, соответствующие моноклинной фазе. В то же время, согласно рентгеноструктурным исследованиям (разд. 4), орторомбическая фаза присутствует в образцах до концентраций $\mathrm{Eu} x=0.8$. Отсутствие в СЛ образца $\left(\mathrm{Lu}_{0.2} \mathrm{Eu}_{0.8}\right)_{2}\left(\mathrm{WO}_{4}\right)_{3}$ линий, характерных для орторомбической фазы, связано, вероятно, с тем, что количество ее в этих образцах мало. Кроме того, интенсивность свечения моноклинной фазы существенно выше, чем орторомбической, поэтому в СЛ этих образцов доминируют полосы, соответствующие свечению моноклинной фазы. Как отмечалось в разд. 5, в ИК-спектрах поглощения образцов, содержащих $80 \% \mathrm{Eu}$, линий, соответствующих орторомбической фазе, также не наблюдается.

Следует отметить, что в СЛ моноклинной фазы $C 2 / c$ $\mathrm{Eu}_{2}\left(\mathrm{MoO}_{4}\right)_{3}$ наибольшую интенсивность имеют полосы с $\lambda_{\max } \sim 612.8$ и $615.1 \mathrm{~nm}$ [3], близкие к полосам, характерным для моноклинной фазы $\mathrm{Eu}_{2}\left(\mathrm{WO}_{4}\right)_{3}$ (табл. 1).

Для не обезвоженных твердых растворов $\left(\mathrm{Lu}_{1-x} \mathrm{Eu}_{x}\right)_{2}\left(\mathrm{WO}_{4}\right)_{3}$ имеется такое же, как и для обезвоженных соединений, соответствие между спектрами люминесценции и структурой в области концентраций $\mathrm{Eu} 0.5 \leq x \leq 1$ (табл. 1). В то же время, при $0.01 \leq x<0.5$, как отмечалось, СЛ приповерхностного слоя и объема образца различаются. Однако и в этой области концентраций Еu наблюдается соответствие между основными максимумами в СЛ при возбуждении объема образца $\left(\lambda_{\mathrm{ex}} \sim 395 \mathrm{~nm}\right)$ и его структурой, как и в обезвоженных соединениях. 
Таблица 1. Спектры люминесценции и структурные характеристики $\left(\mathrm{Lu}_{1-x} \mathrm{Eu}_{x}\right)_{2}\left(\mathrm{WO}_{4}\right)_{3}$

\begin{tabular}{|c|c|c|c|c|c|c|c|c|c|}
\hline \multirow{3}{*}{$\begin{array}{c}\text { Состав } \\
\left(\mathrm{Lu}_{1-x} \mathrm{Eu}_{x}\right)_{2}\left(\mathrm{WO}_{4}\right)_{3} \\
0.01 \leq x<0.1\end{array}$} & \multicolumn{8}{|c|}{$\begin{array}{l}\text { Основные максимумы полос люминесценции образцов, } \mathrm{nm} \\
\qquad\left(\lambda_{\mathrm{ex}} \sim 395 \mathrm{~nm}\right)\end{array}$} & \multirow{4}{*}{$\begin{array}{c}\text { Структура } \\
\text { Орторомбическая (пр. гр. Pbcn) }\end{array}$} \\
\hline & \multicolumn{4}{|c|}{ Обезвоженных } & \multicolumn{4}{|c|}{ Не обезвоженных } & \\
\hline & 608.4 & 612.4 & & & 608.4 & 612.4 & & & \\
\hline $0.1 \leq x<0.5$ & 608.4 & 612.4 & & & 608.4 & 612.4 & & Плечо 615 & \\
\hline$x=0.5$ & 608.4 & & 613.2 & 615.7 & 608.4 & & 613.2 & 615.7 & $\begin{array}{l}\text { Моноклинная (пр. гр. } C 2 / c) \\
\text { Орторомбическая (пр. гр. Pbcn) }\end{array}$ \\
\hline $0.5<x<0.7$ & 608.4 & & 613.2 & 615.7 & 608.4 & & 613.2 & 615.7 & \\
\hline $0.7 \leq x \leq 1$ & & & 613.2 & 615.7 & & & 613.2 & 615.7 & Моноклинная (пр.гр. $C 2 / c)$ \\
\hline
\end{tabular}

Таблица 2. Спектры возбуждения люминесценции и структурные характеристики $\left(\mathrm{Lu}_{1-x} \mathrm{Eu}_{x}\right)_{2}\left(\mathrm{WO}_{4}\right)_{3}$

\begin{tabular}{|c|c|c|c|c|c|c|c|c|}
\hline \multirow{3}{*}{$\begin{array}{c}\text { Состав } \\
\left(\mathrm{Lu}_{1-x} \mathrm{Eu}_{x}\right)_{2}\left(\mathrm{WO}_{4}\right)_{3} \\
0.01<x<0.3 \\
\end{array}$} & \multicolumn{7}{|c|}{$\begin{array}{c}\text { Основные максимумы спектра } \\
\text { возбуждения люминесценции, nm }\end{array}$} & \multirow[t]{2}{*}{ Структура } \\
\hline & \multicolumn{3}{|c|}{ Обезвоженных } & \multicolumn{4}{|c|}{ Не обезвоженных } & \\
\hline & 252 & 394.5 & 465.5 & 304 & & 394.5 & 465.5 & \multirow{2}{*}{ Орторомбическая (пр.гр. $P b c n$ ) } \\
\hline $0.3 \leq x<0.5$ & 252 & 394.5 & 465.5 & $272-274$ & 304 & 394.5 & 465.5 & \\
\hline $0.5 \leq x<0.7$ & $272-275$ & 395.5 & 466.5 & $272-275$ & & 395.5 & 466.5 & $\begin{array}{l}\text { Моноклинная (пр. гр. } C 2 / c) \\
\text { Орторомбическая (пр. гр. Pbcn) }\end{array}$ \\
\hline $0.7 \leq x \leq 1$ & $272-275$ & 395.5 & 466.5 & $272-275$ & & 395.5 & 466.5 & Моноклинная (пр. гр. C2/c) \\
\hline
\end{tabular}

\section{2. Спектры возбуждения люминесценции}

Спектры возбуждения люминесценции (СВЛ) наиболее интенсивных полос свечения вольфраматов $\left(\mathrm{Lu}_{1-x} \mathrm{Eu}_{x}\right)_{2}\left(\mathrm{WO}_{4}\right)_{3}$ представлены на рис. 10. Прежде всего, следует особо подчеркнуть, что в СВЛ как обезвоженных, так и не обезвоженных образцов при всех концентрациях Еu наблюдаются две узкие резонансные полосы с $\lambda_{\max } \sim 394.5-395.5$ и $\sim 465.5-466.5 \mathrm{~nm}$, соответствующие переходам ${ }^{7} \mathrm{~F}_{0} \rightarrow{ }^{5} \mathrm{~L}_{6}$ и ${ }^{7} \mathrm{~F}_{0} \rightarrow{ }^{5} \mathrm{D}_{2}$ в ионах $\mathrm{Eu}^{3+}$. Кроме этих полос, для обезвоженных образцов можно выделить три области концентраций Eu, в которых спектры возбуждения наиболее интенсивных полос люминесценции в ультрафиолетовой области спектра совпадают:

1. При $x=0.01$ в СВЛ наибольшую интенсивность имеет коротковолновая полоса с $\lambda_{\max } \sim 310 \mathrm{~nm}$ (рис. 10 , спектр 1).

2. При $0.01<x<0.5$ наибольшую интенсивность имеет полоса $\lambda_{\max } \sim 252 \mathrm{~nm}$ (рис. 10, спектр 2).

3. При $0.5 \leq x \leq 1$ максимум СВЛ в коротковолновой области спектра имеет широкая полоса с $\lambda_{\max } \sim 272-275 \mathrm{~nm}$ (рис. 10, спектры 3,4).

Как отмечалось, в области концентраций Eu $0.01<x<0.5$ твердый раствор $\left(\mathrm{Lu}_{1-x} \mathrm{Eu}_{x}\right)_{2}\left(\mathrm{WO}_{4}\right)_{3}$ имеет орторомбическую структуру Pbcn. СВЛ, соответствующий этой структуре, в коротковолновой области спектра имеет максимум при $\lambda_{\max } \sim 252 \mathrm{~nm}$ (рис. 10, спектр 2). При $0.5 \leq x \leq 1$ в СВЛ наибольшую интенсивность в коротковолновой области спектра имеет полоса с $\lambda_{\max } \sim 272-275 \mathrm{~nm}$, характерная для моноклинной структуры $C 2 / c[2,3]$.

Для не обезвоженных образцов $\left(\mathrm{Lu}_{1-x} \mathrm{Eu}_{x}\right)_{2}\left(\mathrm{WO}_{4}\right)_{3}$ в интервале концентраций $\mathrm{Eu} 0.01 \leq x \leq 1$ можно выделить три подинтервала, где СВЛ в ультрафиолетовой области остаются практически одинаковыми:

1. При $0.01 \leq x<0.3$ наибольшую интенсивность имеет полоса с $\lambda_{\max } \sim 304 \mathrm{~nm}$ (рис. 10, спектр 5).

2. При $0.3 \leq x<0.5$ наблюдаются две широкие полосы с $\lambda_{\max } \sim 272-274$ и $\sim 304 \mathrm{~nm}$ (рис. 10, спектр 6).

3. При $0.5 \leq x \leq 1$ в СВЛ наблюдается полоса с $\lambda_{\max } \sim 272-274 \mathrm{~nm}$ (рис. 10, спектр 7), совпадающая с полосой в СВЛ обезвоженных образцов и характерная для структуры $C 2 / c$.

Важно отметить, что в не обезвоженных соединениях для орторомбической структуры Pbcn при концентрациях $\mathrm{Eu} 0.01 \leq x<0.3$ характерна полоса с $\lambda_{\max } \sim 304 \mathrm{~nm}$, а для $0.3 \leq x<0.5$ этой структуре соответствуют две полосы с $\lambda_{\max } \sim 272-274$ и $\sim 300 \mathrm{~nm}$, тогда как для обезвоженных образцов при $0.01<x<0.5$ наблюдается только одна более коротковолновая полоса при $\lambda_{\max } \sim 252 \mathrm{~nm}$.

Также следует отметить, что в области концентраций $\mathrm{Eu} 0.5 \leq x \leq 1$ для обезвоженных и не обезвоженных образцов СЛ и СВЛ абсолютно идентичны. 


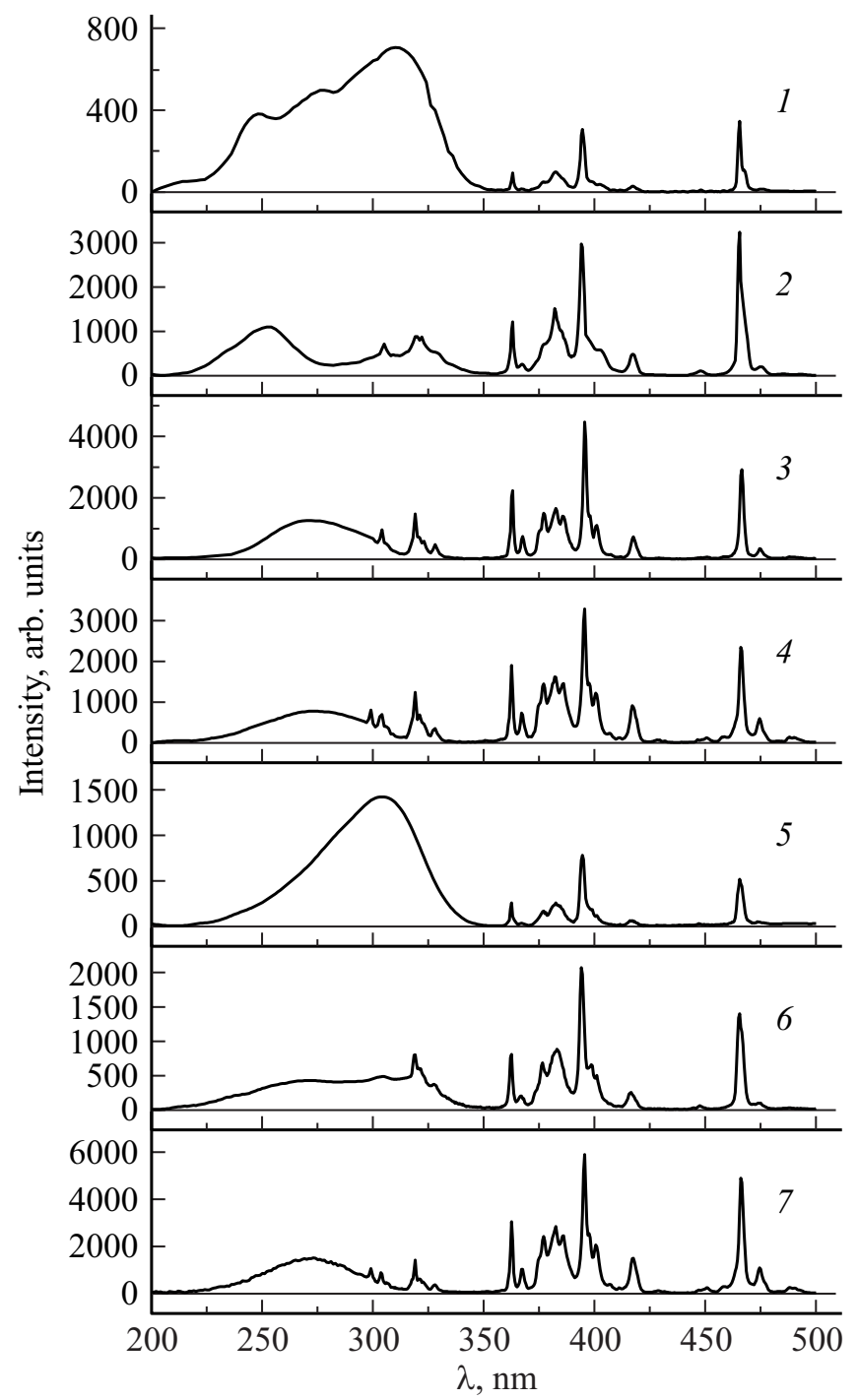

Рис. 10. Спектры возбуждения люминесценции вольфраматов $\left(\mathrm{Lu}_{1-x} \mathrm{Eu}_{x}\right)_{2}\left(\mathrm{WO}_{4}\right)_{3} .1-\left(\mathrm{Lu}_{0.99} \mathrm{Eu}_{0.01}\right)_{2}\left(\mathrm{WO}_{4}\right)_{3}$; $2-\left(\mathrm{Lu}_{0.7} \mathrm{Eu}_{0.3}\right)_{2}\left(\mathrm{WO}_{4}\right)_{3} ; 3-\left(\mathrm{Lu}_{0.5} \mathrm{Eu}_{0.5}\right)_{2}\left(\mathrm{WO}_{4}\right)_{3}$; $4-\mathrm{Eu}_{2}\left(\mathrm{MoO}_{4}\right)_{3} ; 5-\left(\mathrm{Lu}_{0.9} \mathrm{Eu}_{0.1}\right)_{2}\left(\mathrm{WO}_{4}\right)_{3}$; $6-\left(\mathrm{Lu}_{0.6} \mathrm{Eu}_{0.4}\right)_{2}\left(\mathrm{WO}_{4}\right)_{3} ; 7-\left(\mathrm{Lu}_{0.2} \mathrm{Eu}_{0.8}\right)_{2}\left(\mathrm{WO}_{4}\right)_{3} ; 1,2,5,6-$ максимум свечения $\lambda_{\max }=612.4 \mathrm{~nm} ; 3,4,7-\lambda_{\max }=615.7 \mathrm{~nm}$. Спектры 1-4 - для обезвоженных образцов, 5-7 - для не обезвоженных образцов.

Таким образом, изменение структурного состояния твердых растворов $\left(\mathrm{Lu}_{1-x} \mathrm{Eu}_{x}\right)_{2}\left(\mathrm{WO}_{4}\right)_{3}$ приводит к значительным изменениям СВЛ только в коротковолновой области спектра (табл. 2). В то же время, как показано в работе [11], СВЛ $\left(\mathrm{Lu}_{1-x} \mathrm{Eu}_{x}\right)_{2}\left(\mathrm{MoO}_{4}\right)_{3}$, в отличие от $\left(\mathrm{Lu}_{1-x} \mathrm{Eu}_{x}\right)_{2}\left(\mathrm{WO}_{4}\right)_{3}$, практически не изменяется при изменении структурного состояния образца.

Как отмечалось в разд. 4, орторомбическая фаза присутствует в не обезвоженных образцах до концентраций Eu $x=0.8$. Однако в спектрах возбуждения люминесценции полос, характерных для орторомбической фазы при $0.5 \leq x \leq 1$, не наблюдается. Это связано, вероятно, с тем, что интенсивность свечения моно- клинной фазы значительно выше, чем орторомбической, поэтому в СВЛ этих образцов доминируют полосы, соответствующие свечению $C 2 / c$-фазы.

По данным литературы, в СВЛ молибдатов и вольфраматов редкоземельных ионов, содержащих $\mathrm{Eu}^{3+}$, в ультрафиолетовой области спектра могут наблюдаться две полосы: коротковолновая с $\lambda_{\max } \sim 250-285 \mathrm{~nm}$, соответствующая переносу заряда от $\mathrm{O}^{2-}$ к $\mathrm{Eu}^{3+}$, и более длинноволновая с $\lambda_{\max } \sim 300-315 \mathrm{~nm}$, обусловленная переносом заряда от $\left(\mathrm{WO}_{4}\right)^{2-}$ к $\mathrm{Eu}^{3+}[26,27]$. Важно также отметить, что полоса с $\lambda_{\max } \sim 304 \mathrm{~nm} \mathrm{в} \mathrm{СВЛ}$ наблюдается также в твердом растворе $\mathrm{Lu}_{1-x} \mathrm{Eu}_{x} \mathrm{WO}_{6}$ и также является полосой с переносом заряда $[28,29]$. Поэтому наличие полосы с $\lambda_{\max } \sim 304 \mathrm{~nm}$ в СВЛ не обезвоженных соединений $\left(\mathrm{Lu}_{1-x} \mathrm{Eu}_{x}\right)_{2}\left(\mathrm{WO}_{4}\right)_{3}$ может быть обусловлено также тем, что эти образцы являются гигроскопичными. При поглощении воды изменяется окружение ионов $\mathrm{Eu}^{3+}$ кислородом, и оно становится таким же, как и в соединении $\mathrm{Lu}_{1-x} \mathrm{Eu}_{x} \mathrm{WO}_{6}$. В то же время, полоса с $\lambda_{\max } \sim 310 \mathrm{~nm}$ в СВЛ обезвоженных соединений $\left(\mathrm{Lu}_{0.99} \mathrm{Eu}_{0.01}\right)_{2}\left(\mathrm{WO}_{4}\right)_{3}$, скорее всего, обусловлена переносом заряда от $\left(\mathrm{WO}_{4}\right)^{2-}$ к $\mathrm{Eu}^{3+}$.

Как известно, $R E^{3+}$-ионы чувствительны к ближайшему окружению [30,31], поэтому по изменению спектральных характеристик $R E^{3+}$-ионов можно судить об изменении их локального окружения даже тогда, когда дальний порядок (определенная структурная модификация) отсутствует.

Как уже отмечалось, СЛ обезвоженных образцов $\left(\mathrm{Lu}_{1-x} \mathrm{Eu}_{x}\right)_{2}\left(\mathrm{WO}_{4}\right)_{3}$ не зависят от длины волны возбуждающего света - СЛ при возбуждении приповерхностного слоя образца $\left(\lambda_{\mathrm{ex}}=250-310 \mathrm{~nm}\right)$ и его объема $\left(\lambda_{\mathrm{ex}} \sim 395 \mathrm{~nm}\right)$ совпадают (рис. 8, спектры 2 и 3, 4 и 5), поэтому ближайшее окружение ионов $\mathrm{Eu}^{3+}$ в этих образцах остается неизменным во всем объеме образца. Это свидетельствует о том, что исследованные соединения структурно однородны. Данный вывод важен потому, что при рентгенофазовом анализе образцов мы получаем информацию о структуре образца, усредненную по его объему, определяемому глубиной проникновения рентгеновского излучения, которая составляет в наших экспериментах $\sim 5 \mu \mathrm{m}$ и превышает средний размер исследуемых микрокристаллов (рис. 2). Поэтому при рентгенофазовом анализе мы получаем информацию о структуре всего образца. В то же время, структуры поверхности и объема образца могут существенно отличаться [3,5]. Именно такая ситуация характерна для не обезвоженных образцов $\left(\mathrm{Lu}_{1-x} \mathrm{Eu}_{x}\right)_{2}\left(\mathrm{WO}_{4}\right)_{3}$ при концентрациях $\mathrm{Eu} 0.1 \leq x<0.5$. Эти образцы являются неоднородными, так как спектры люминесценции приповерхностного слоя и объема образца существенно различаются (рис. 9, спектры 2 и 3 ).

На рис. 11, $a$ и $b$ представлены зависимости интенсивности полос, имеющих максимальную интенсивность в СЛ, для обезвоженных и не обезвоженных образцов от концентрации ионов $\mathrm{Eu}(x)$ при возбуждении соединений $\left(\mathrm{Lu}_{1-x} \mathrm{Eu}_{x}\right)_{2}\left(\mathrm{WO}_{4}\right)_{3}$ светом в полосах с переносом 


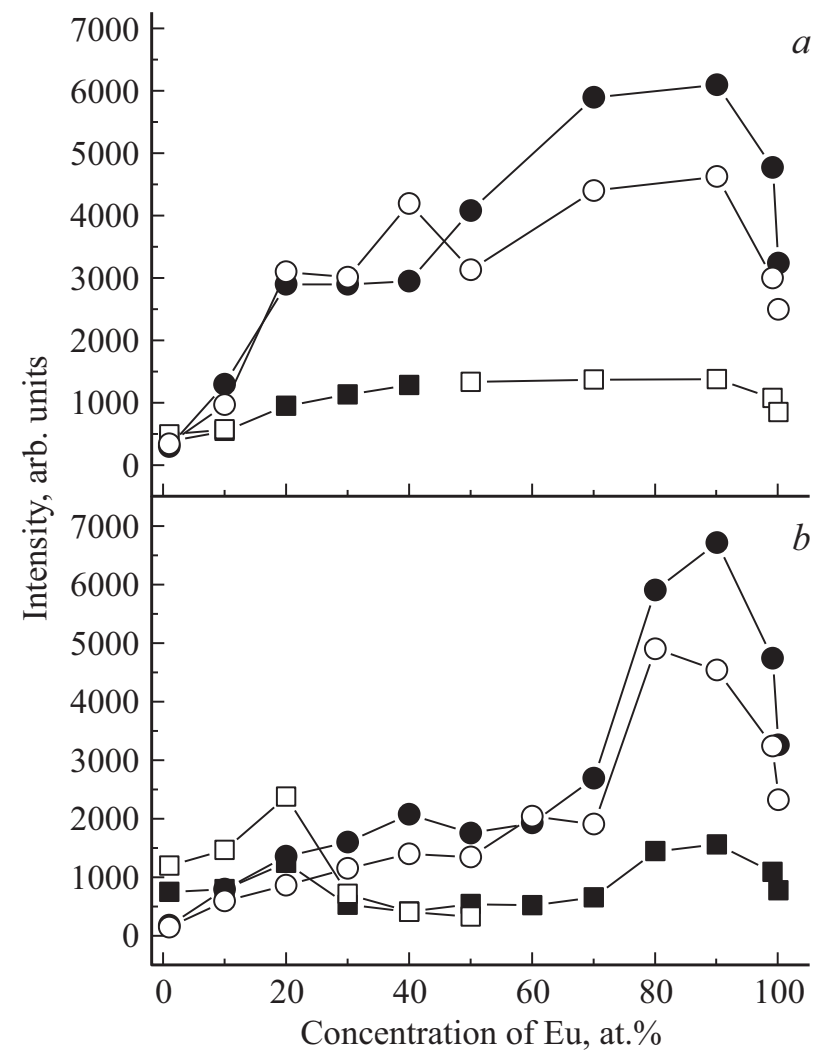

Рис. 11. Зависимости свечения вольфраматов $\left(\mathrm{Lu}_{1-x} \mathrm{Eu}_{x}\right)_{2}\left(\mathrm{WO}_{4}\right)_{3}$ от концентрации $\mathrm{Eu} . \quad a-$ зависимости имеющих максимальную интенсивность полос свечения обезвоженных образцов при возбуждении светом: - $-\lambda_{\mathrm{ex}}=252 \mathrm{~nm} ; \quad \square-\lambda_{\mathrm{ex}}=275 \mathrm{~nm} ; \quad-\quad \lambda_{\mathrm{ex}}=395 \mathrm{~nm}$; $\circ-\lambda_{\mathrm{ex}}=466 \mathrm{~nm}$; при $0.01 \leq x \leq 0.4-$ максимум свечения $\lambda_{\max }=612.4 \mathrm{~nm} ;$ при $0.5 \leq x \leq 1-\lambda_{\max }=615.7 \mathrm{~nm} ; b-$ зависимости имеющих максимальную интенсивность полос свечения не обезвоженных образцов при возбуждении светом: - $-\lambda_{\mathrm{ex}}=275 \mathrm{~nm} ; \square-\lambda_{\mathrm{ex}}=304 \mathrm{~nm} ;--\lambda_{\mathrm{ex}}=395 \mathrm{~nm}$; $\circ-\lambda_{\mathrm{ex}}=466 \mathrm{~nm}$; при $0.01 \leq x \leq 0.4-$ максимум свечения $\lambda_{\max }=612.4 \mathrm{~nm}$; при $0.5 \leq x \leq 1-\lambda_{\max }=615.7 \mathrm{~nm}$.

заряда с $\lambda \sim 250$ и $272-275 \mathrm{~nm}$ (для обезвоженных) и 306 и $\sim 272-275 \mathrm{~nm}$ (для не обезвоженных), а также в наиболее интенсивных резонансных полосах $\mathrm{Eu}^{3+} \sim 395$ и $\sim 466 \mathrm{~nm}$. Как видно из рис. $11, a$, интенсивность свечения при возбуждении в ППЗ для обезвоженных образцов практически не изменяется при концентрациях $\mathrm{Eu}$ 20-100\%, тогда как для не обезвоженных образцов максимум интенсивности свечения наблюдается при 20\% (рис. $11, b$ ) при возбуждении светом с $\lambda_{\max } \sim 306 \mathrm{~nm}$.

При возбуждении светом, соответствующим резонансным полосам поглощения с $\lambda_{\max } \sim 395$ и $466 \mathrm{~nm}$, максимальные интенсивности свечения $\left(J_{\max }\right)$ для обезвоженных и не обезвоженных образцов близки и наблюдаются при $x=0.9$ (рис. 11, $a$ и $b$ ) при возбуждении светом с $\lambda_{\max }=395 \mathrm{~nm}$ и составляют 6100 и $6700 \mathrm{arb}$ units соответственно. Следует отметить, что в твердых растворах молибдатов $\left(\mathrm{Lu}_{1-x} \mathrm{Eu}_{x}\right)_{2}\left(\mathrm{MoO}_{4}\right)_{3} J_{\max }$ наблюдается при $x=0.8$ при возбуждении светом с $\lambda_{\max }=395 \mathrm{~nm}$ и со- ставляет 6500 arb. units [11], что близко к максимальным значениям интенсивности свечения $\left(\mathrm{Lu}_{1-x} \mathrm{Eu}_{x}\right)_{2}\left(\mathrm{WO}_{4}\right)_{3}$.

Как известно, электронные переходы между состояниями свободных ионов $\mathrm{Eu}^{3+}$, принадлежащих одной конфигурации, в нашем случае $4 f^{n}$, запрещены по четности $[30,31]$. Под действием кристаллического поля этот запрет частично снимается. При замещении ионов $\mathrm{Eu}^{3+}$, имеющих ионный радиус $0.950 \AA$, ионами $\mathrm{Lu}^{3+}$, имеющих значительно меньший ионный радиус $(0.848 \AA)$ [17], величина кристаллического поля вокруг $\mathrm{Eu}^{3+}$ возрастает, что приводит к еще большему снятию запрета и увеличению интенсивности свечения европия. Замещение даже $1 \%$ ионов $\mathrm{Eu}^{3+}$ ионами $\mathrm{Lu}^{3+}$ приводит к заметному увеличению интенсивности свечения при резонансном возбуждении ионов $\mathrm{Eu}$ (рис. 11, $a$ и $b$ ).

Исследование зависимости интенсивности свечения от концентрации $\mathrm{Eu}$ в соединениях $\left(\mathrm{Lu}_{1-x} \mathrm{Eu}_{x}\right)_{2}\left(\mathrm{WO}_{4}\right)_{3}$ при возбуждении в полосах с переносом заряда и в резонансных полосах ионов $\mathrm{Eu}^{3+}$ показало, что зависимость $J_{\max }$ от соотношения между концентрациями $\mathrm{Eu}$ и $\mathrm{Lu}$ является более сильной, чем зависимость $J_{\max }$ от структурного состояния этих соединений (рис. 11, $a$ и $b$ ).

В то же время и СЛ, и СВЛ ионов $\mathrm{Eu}^{3+}$ существенно зависят от структурного состояния образца (табл. 1 и 2).

\section{7. Заключение}

1. Установлено соответствие между структурной модификацией и спектральными характеристиками люминесценции и ИК-поглощения твердых растворов вольфраматов $\left(\mathrm{Lu}_{1-x} \mathrm{Eu}_{x}\right)_{2}\left(\mathrm{WO}_{4}\right)_{3}$ в широкой области концентрации $\mathrm{Eu}(0 \leq x \leq 1)$.

2. С ростом концентрации Еu происходит последовательная смена двух типов кристаллических фаз. В интервале $0 \leq x \leq 0.4$ твердый раствор вольфраматов является однофазным с орторомбической структурой Pbcn. В интервале значений $0.4<x \leq 0.8$ наряду с орторомбической появляется моноклинная фаза $C 2 / c$, а при $x>0.8$ твердый раствор является также однофазным с моноклинной структурой $C 2 / c$.

3. Изучена изотерма адсорбции воды образцами вольфраматов и влияние воды на спектральные и структурные характеристики вольфраматов.

4. Наблюдается уменьшение объема элементарной ячейки орторомбической фазы образца, обусловленное поглощением воды.

5. Вхождение воды в структуру $\left(\mathrm{Lu}_{1-x} \mathrm{Eu}_{x}\right)_{2}\left(\mathrm{WO}_{4}\right)_{3}$ приводит к исчезновению в ИК-спектрах линий 970 и $999 \mathrm{~cm}^{-1}$, соответствующих симметричным валентным колебаниям $v_{1}$ тетраэдра $\mathrm{WO}_{4}$.

6. Орторомбической фазе Pbcn твердых растворов вольфраматов соответствует спектр люминесценции, содержащий две наиболее интенсивные полосы с $\lambda_{\max } \sim 608.4$ и $\sim 612.4 \mathrm{~nm}$ для обезвоженных и не обезвоженных образцов.

7. Спектры возбуждения люминесценции обезвоженных и не обезвоженных образцов, соответствующих орторомбической фазе, отличаются только в ультрафиолетовой области спектра. Для обезвоженных образцов при 
$0.01<x<0.5$ наиболее интенсивной является полоса с $\lambda_{\max } \sim 250 \mathrm{~nm}$. Для необезвоженных соединений при $0.01<x<0.3$ в СВЛ наблюдается полоса $\sim 304 \mathrm{~nm}$, а при $0.3 \leq x<0.5-$ полосы $\sim 272-275$ и $\sim 304 \mathrm{~nm}$. Кроме того, наиболее интенсивными являются полосы с $\lambda_{\max } \sim 394.5$ и $\sim 465.5 \mathrm{~nm}$.

8. В СЛ моноклинной фазы $C 2 / c$, которая не является гигроскопичной, наиболее интенсивными являются полосы с $\lambda_{\max } \sim 613.2$ и $\sim 615.7 \mathrm{~nm}$, а в СВЛ - полосы с $\lambda_{\text {max }} \sim 272-275, \sim 395.5$ и $\sim 466.5 \mathrm{~nm}$.

Образцы $\left(\mathrm{Lu}_{1-x} \mathrm{Eu}_{x}\right)_{2}\left(\mathrm{WO}_{4}\right)_{3}$ при $0.5 \leq x \leq 0.8$ являются двухфазными, в них одновременно присутствуют орторомбическая и моноклинная фазы, причем доля последней возрастает с увеличением $x$. Поскольку интенсивность свечения моноклинной фазы существенно выше, чем орторомбической, в спектрах люминесценции и возбуждения люминесценции этих образцов доминируют полосы, соответствующие свечению моноклинной фазы. При $0.8<x \leq 1$ образец является однофазным, он имеет моноклинную структуру и в спектрах наблюдаются полосы, соответствующие только $C 2 / c$-структуре.

9. В отличие от исследованных в работе [11] твердых растворов молибдатов $\mathrm{Lu}$ и $\mathrm{Eu}$, изменение структурного состояния приводит не только к изменению спектров люминесценции, но и спектров возбуждения люминесценции вольфраматов.

10. Показано, что максимальная интенсивность свечения ионов $\mathrm{Eu}^{3+}$ при возбуждении светом, соответствующим резонансным полосам поглощения $\left(\lambda_{\mathrm{ex}} \sim 395\right.$ и $\left.\sim 466 \mathrm{~nm}\right)$, наблюдается для соединения $\left(\mathrm{Lu}_{0.1} \mathrm{Eu}_{0.9}\right)_{2}\left(\mathrm{WO}_{4}\right)_{3}$. Это соединение не гигроскопично, имеет высокую интенсивность свечения и может быть использовано в качестве эффективного красного люминофора для светодиодных источников света.

\section{Благодарности}

Авторы выражают благодарность ЦКП НО Института физики твердого тела РАН за исследование образцов методом ИК-спектроскопии, а также их морфологии. Выражается благодарность Н.Ф. Прокопюку за помощь в проведении экспериментов.

\section{Финансирование работы}

Работа выполнена в рамках госзадания ИФТТ РАН.

\section{Конфликт интересов}

Авторы заявляют, что у них нет конфликта интересов.

\section{Список литературы}

[1] Y.H. Zhou, J. Lin, S.B. Wang, H.J. Zhang. Opt. Mater. 20, 13 (2002).

[2] V. Dmitriev, V. Sinisyn, R. Dilanyan, D. Machon, A. Kuznetsov, E. Ponyatovsky, G. Lucazeau, H.-P. Weber. J. Phys. Chem. Solids 64, 307 (2003).
[3] А.П. Киселев, С.3. Шмурак, Б.С. Редькин, В.В. Синицын, И.М. Шмытько, Е.А. Кудренко, Е.Г. Понятовский. ФТТ 48, 1458 (2006).

[4] S.Z. Shmurak, A.P. Kiselev, N.V. Klassen, V.V. Sinitsyn, I.M. Shmyt'ko, B.S. Red'kin, S.S. Khasanov. IEEE Trans. Nucl. Sci. 55, 1128 (2008).

[5] С.3. Шмурак, А.П. Киселев, Д.М. Курмашева, Б.С. Редькин, В.В. Синицын. ЖТФ 137, 867 (2010).

[6] С.3. Шмурак, В.В. Кедров, А.П. Киселев, И.М. Шмытько. ФTT 57, 19 (2015).

[7] J. Yang, C. Li, X. Zhang, Z. Quan, C. Zhang, H. Li, J. Lin. Chem. Eur. J. 14, 4336 (2008).

[8] J. Hälsö. Inorg. Chim. Acta 139, 257 (1987).

[9] С.З. Шмурак, В.В. Кедров, А.П. Киселев, И.М. Шмытько. ФTT 57, 19 (2015).

[10] С.3. Шмурак, В.В. Кедров, А.П. Киселев, Т.Н. Фурсова, И.М. Шмытько. ФТТ 57, 1558 (2015).

[11] С.3. Шмурак, В.В. Кедров, А.П. Киселев, Т.Н. Фурсова, И.И. Зверькова, С.С. Хасанов. ФТТ 61, 747 (2019).

[12] H.Y. Chen. Mater. Res. Bull. 14, 1583 (1979).

[13] В.А. Ефремов, Б.И. Лазоряк, В.К. Трунов. Кристаллография 26, 72 (1981).

[14] E.M. Levin, R.S. Roth, J.B. Martin. Am. Mineral. 46, 1030 (1961).

[15] L.N. Brixner, J.R. Barkley, W. Jeitschko. In: Handbook on the Physics and Chemistry of Rare Earth / Eds. K.A. Gschneidner, Jr.L. Eyring, North-Holland Publishing Company (1979). P. 609.

[16] K. Nassau, H.J. Levinstein, G.M. Loiacono. J. Phys. Chem. Solids 26, 1805 (1965).

[17] Н.С. Ахметов. Неорганическая химия. Высш. шк., М. (1975). C. 548

[18] Z.Y. Li, W.B. Song, E.J. Liang. J. Phys. Chem. C 115, 17806 (2011).

[19] К. Накамото. Инфракрасные спектры неорганических и координационных соединений. Мир, М. (1968). С. 151.

[20] J. Hanuza, M. Maczka, K. Hermanowicz, M. Andruszkiewicz, A. Pietraszko, W. Strek, P. Deren. J. Solid State Chem. 105, 49 (1993).

[21] L.J. Burcham, I.E. Wachs. Spectrochimica Acta A 54, 1355 (1998).

[22] M. Maczka, K. Hermanowicza, J. Hanuza. J. Molecular Struct. 744-747, 283 (2005).

[23] G. Blasse, M. Ouwerkerk. J. Electrochem. Soc.: Solid-State Sci. Technol. 27, 429 (1980).

[24] M. Rahimi-Nasrabadi, S.M. Pourmortazavi, M.R. Ganjali, A.R. Banan, F. Ahmadi. J. Molecular Struct. 1074, 85 (2014).

[25] A.W. Sleight, L.H. Brixner. J. Solid State Chem. 7, 172 (1973).

[26] S. Neeraj, N. Kijima, A. Cheetham. Chem. Phys. Lett. 387, 2 (2004).

[27] A. Xie, X. Yuan, F. Wang, Y. Shi, J. Li, L. Liu, Z. Mu. J. Alloys Compd. 501, 124 (2010).

[28] Z. Zhang, H. Zhang, C. Duan, J. Yuan, X. Wang, D. Xiong, H. Chen, J. Zhao. J. Alloys Compd. 466, 258 (2008).

[29] G. Blasse, G.J. Dirksen, L.H. Brixner. J. Solid State Chem. 46, 294 (1983).

[30] М.А. Ельяшевич. Спектроскопия редких земель. ГИТТЛ, M. (1953). C. 456.

[31] М.И. Гайдук, В.Ф. Золин, Л.С. Гайгерова. Спектры люминесценции европия. Наука, М. (1974). С. 195.

Редактор Е.В. Толстякова 